\title{
Potential Targets and Clinical Value of MiR- 224-5p in Cancers of the Digestive Tract
}

\author{
Lu Zhang $^{\mathrm{a}}$ Lan-shan Huang ${ }^{\mathrm{a}}$ Gang Chen ${ }^{\mathrm{a}}$ Zhen-bo Feng ${ }^{\mathrm{a}}$ \\ aDepartment of Pathology, First Affiliated Hospital of Guangxi Medical University, Nanning, Guangxi \\ Zhuang Autonomous Region, China
}

\section{Key Words}

Microrna $\cdot$ MiR-224-5p • Digestive system cancers $•$ Bioinformatics

\begin{abstract}
Background/Aims: MicroRNAs participate in various biological processes in malignant tumors. However, the mechanisms of miR-224-5p in digestive system cancers are not fully understood. A comprehensive investigation of the clinical value and potential targets of miR224-5p in cancers of the digestive tract is necessary. Methods: Expression profiling data and related-prognostic data of miR-224-5p were acquired from Gene Expression Omnibus, The Cancer Genome Atlas, ArrayExpress, and published literature. The potential target mRNAs of miR-224-5p were predicted using bioinformatics methods and finally annotated using Gene Ontology (GO) annotation and Kyoto Encyclopedia of Genes and Genomes (KEGG) pathway enrichment analysis. Results: MiR-224-5p is up-regulated in digestive system cancers ( $\mathrm{SMD}=0.69,95 \% \mathrm{CI}: 0.43-0.96, \mathrm{P}<0.0001$ ) and exhibits a moderate diagnostic ability (AUC $=0.84$, 95\% CI: $0.80-0.87)$. Our data also demonstrated that miR-224-5p is statistically significantly correlated with overall survival univariate analysis ( $\mathrm{HR}=1.69,95 \% \mathrm{CI}: 1.15-2.49, \mathrm{P}=0.007)$ and multivariate analysis ( $\mathrm{HR}=2.39,95 \% \mathrm{CI}: 1.74-3.30, \mathrm{P}<0.0001)$. In total, 388 potential miR-224$5 p$ target mRNAs were predicted by bioinformatics methods. GO annotation analysis revealed that the top terms of miR-224-5p in biological process, cellular component and molecular function were system development, neuron part, and transcriptional activator activity, RNA polymerase II core promoter proximal region sequence-specific binding, respectively. Moreover, eight pathways were identified in KEGG pathway enrichment analysis. Conclusions: MiR-224$5 p$ is up-regulated and has the potential to become a diagnostic and prognostic biomarker in digestive system cancers. MiR-224-5p might play vital roles in cancers of the digestive tract but the exact molecular mechanisms need further study and verification.
\end{abstract}

\section{Introduction}

(C) 2017 The Author(s)

Published by S. Karger AG, Basel

Digestive system cancers have the common histological origin of ducts and glands. According to the latest Cancer Statistics, a total of 310, 440 estimated new cases and 157, 700 estimated deaths occurred as a result of digestive system cancers in the United States [1]. Similarly, the morbidity and mortality of digestive system cancers are also increasing in

Zhen-bo Feng

KARGER
Department of Pathology, the First Affiliated Hospital of Guangxi Medical University, 6 Shuangyong Road, Nanning, Guangxi Zhuang Autonomous Region 530021, (P.R. China) Fax+86 771 5352194, E-Mail Fengzhenbo_GXMU@163.com 
China. From top to bottom, esophageal cancer (ESCA), gastric cancer (GC), hepatocellular carcinoma (HCC), biliary tract cancer (BTC), pancreatic cancer (PC), and colorectal cancer (CRC) are the most commonly diagnosed cancers in the digestive tract. However, their prognoses remain fairly poor due to increasing prevalence, late diagnosis, continuous drug resistance and recurrence. Thus, it is necessary to discover potential novel diagnostic and prognostic biomarkers for digestive system cancers.

MicroRNAs (miRNAs) are endogenous small noncoding RNAs that are typically 1924 nucleotides in length. MicroRNAs regulate possible target mRNAs. Numerous studies have concentrated on the roles of miRNAs, indicating that miRNAs participate in a variety of biological processes and signal pathways [2-4]. The roles of miRNAs in the diagnosis, prognosis, and therapeutic prediction of human malignancies have also been discovered [57].

The mature miRNA microRNA-224-5p (miR-224-5p, previously named miR-224) participates in a series of biological processes, including cell proliferation, migration and invasion, in various malignancies [8-12]. To date, numerous independent small sample studies have assessed the role of miR-224-5p in digestive system cancers, such as GC [13], CRC [14], HCC [15] and ESCA [16]. However, no comprehensive investigation of the clinical value and potential targets of miR-224-5p in digestive system cancers has been reported to date.

In this study, we first gathered data sources from the Gene Expression Omnibus (GEO), The Cancer Genome Atlas (TCGA), ArrayExpress, and related-prognostic published literature on miR-224-5p to estimate the clinical value of miR-224-5p in digestive system cancers (Fig. 1). Twelve miRNA-target prediction programs were applied to predict the potential target mRNAs of miR-224-5p, and the results were merged to make the conclusion more credible. Subsequently, bioinformatics analyses, including Gene Ontology (G0) annotation and Kyoto Encyclopedia of Genes and Genomes (KEGG) pathway enrichment analysis, of potential miR224-5p target mRNAs were performed to investigate the relevant signaling pathways of miR224-5p target genes and the potential molecular mechanisms of miR-224-5p in digestive system malignancies.

\section{Materials and Methods}

\section{Data collection}

MiR-224-5p microarray and RNA-seq datasets of digestive system cancers were collected from GEO (http://www.ncbi.nlm.nih.gov/geo/), TCGA (http://cancergenome.nih.gov/) and ArrayExpress (http:// www.ebi.ac.uk/arrayexpress/). Related prognostic studies of miR-224-5p in digestive system cancers were also identified using PubMed, Web of Science, Wiley Online Library, Cochrane Library, Science Direct, Chinese CNKI and Wan Fang database searches of publications up to July 25, 2017. The search strategy was as follows: (malignant* OR neoplasm* OR carcinoma OR cancer OR tumor) AND (miR-224 OR miRNA-224 OR microRNA-224 OR miR-224-5p OR miRNA-224-5p OR microRNA-224-5p).

\section{Selection criteria}

The inclusion criteria for microarray and RNA-seq datasets of miR-224-5p in digestive carcinomas were as follows: (1) cancer group samples were identified as a digestive system carcinoma; (2) the species were humans; (3) each dataset included a cancer group and a noncancerous group; (4) expression profiling data of miR-224-5p could be acquired.

The following inclusion criteria for related-prognostic data from published studies of miR-224-5p in digestive system cancers were employed: (1) study objects were histologically proven as a digestive system carcinoma; (2) study objects were humans; (3) the association between miR-224-5p expression and survival outcome was revealed; (4) sufficient survival data to evaluate the Hazard Ratio (HR) and 95\% Confidence Interval (CI) were available. 
Fig. 1. Flow-chart of data sources included in this study.

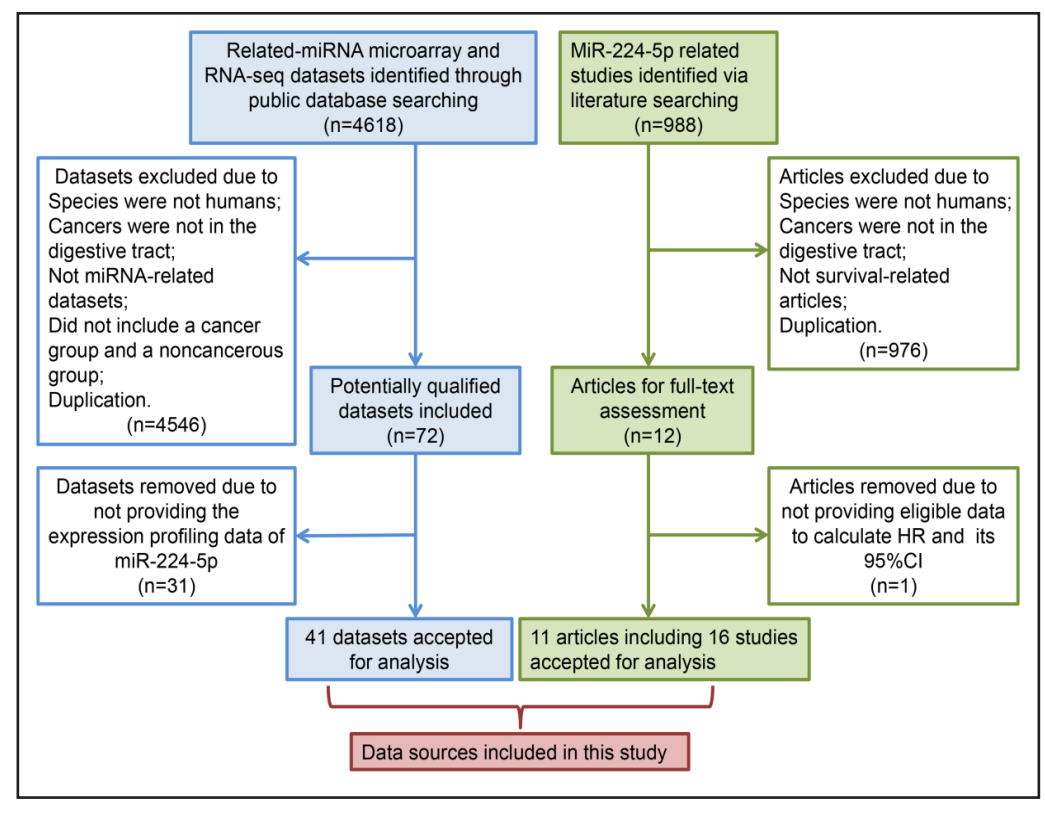

\section{Data extraction}

Two reviewers collected the data individually from all included studies. The main extracted data in the miR-224-5p expression microarray or RNA-seq datasets consisted of data source, country, cancer type, platform, sample sizes and the expression data of miR-224-5p. For related-prognostic published literatures and datasets, data, such as first author, country, cancer type, test method, sample size, analysis method, HR and the $95 \% \mathrm{CI}$, were evaluated. Considering discrepancies, disagreements were determined via discussion.

\section{Target $m$ RNAs prediction}

Potential target mRNAs of miR-224-5p were predicted by miRWalk 2.0 (http://zmf.umm.uniheidelberg.de/apps/zmf/mirwalk2/), which incorporates 12 existing miRNA-target prediction programs: miRWalk, miRDB, miRMap, miRNAMap, miRanda, mirbridge, Microt4, Pictar2, PITA, RNA22, RNAhybrid, and Targetscan. Only genes that were simultaneously predicted by at least eight online prediction tools were selected for further functional and pathway enrichment analysis.

\section{GO annotation and KEGG pathway enrichment analysis}

To explore functional annotation and pathway enrichment of the extracted target mRNAs of miR-224$5 p$, we performed GO annotation and KEGG pathway enrichment analysis using the Database for Annotation, Visualization and Integrated Discovery (DAVID; https://david.ncifcrf.gov/), a functional enrichment analysis web tool. In DAVID, GO annotation analysis was divided into three GO categories, including Biological Process (BP), Cellular Component (CC) and Molecular Function (MF). KEGG pathway enrichment analyses were listed according to P-value. Only entries with a P-value $<0.05$ were chosen for analysis.

\section{Statistical analysis}

The expression profiling data of miR-224-5p were log2-transformed. SPSS 22.0 (IBM, New York, USA) was applied to calculate the mean and standard deviation of miR-224-5p expression values. Stata Version 12.0 (StataCorp, College Station, TX, USA) was used to assess the pooled Standard Mean Deviation (SMD) with its 95\% CI. When SMD was greater than zero and its 95\% CI did not contain a zero, we could draw the conclusion that miR-224-5p expression level in the cancer group was increased compared with the normal control group, and the result was statistically significant.

To investigate the diagnostic value of miR-224-5p in digestive system neoplasms, Summary Receiver Operating Characteristic (SROC) curves and the Areas Under the Curves (AUCs) with their 95\% CIs were analyzed using Stata Version 12.0. An AUC value of 0.5 0.7 suggested poor evidence, 0.7 0.9 represented moderate evidence, and greater than 0.9 indicated high evidence for diagnosis.

HRs with 95\% CIs were pooled to evaluate the prognostic value of miR-224-5p in digestive system neoplasms and were acquired via three methods: (1) directly reported in the literature; (2) extracted from 
Table 1. Characteristics of 41 microarray and RNA-seq datasets included in this study. BTC: biliary tract cancer; CRC: colorectal cancer; ESCA: esophageal cancer; GC: gastric cancer; PC: pancreatic cancer; HCC: hepatocellular carcinoma; SD: standard deviation; Mean1 \pm SD1: expression level of miR-224-5p in the cancer group; Mean2 \pm SD2: expression level of miR-224-5p in the normal control group

\begin{tabular}{|c|c|c|c|c|c|c|c|c|}
\hline Number & Data source & Country & $\begin{array}{c}\text { Cancer } \\
\text { type }\end{array}$ & Platform & $\begin{array}{l}\text { Cancer } \\
\text { group }\end{array}$ & $\begin{array}{l}\text { Normal } \\
\text { control }\end{array}$ & Mean1士SD1 & Mean2 \pm SD2 \\
\hline 1 & GE0:GSE47764 & China & BTC & GPL11487 & 3 & 3 & $4.87 \pm 0.58$ & $5.26 \pm 1.23$ \\
\hline 2 & GE0:GSE53870 & China & BTC & GPL18118 & 63 & 9 & $9.08 \pm 0.33$ & $9.32 \pm 0.20$ \\
\hline 3 & GE0:GSE7828 & USA & CRC & GPL4700 & 79 & 79 & $9.23 \pm 0.70$ & $9.23 \pm 0.74$ \\
\hline 4 & GE0:GSE10259 & USA & CRC & GPL4411 & 59 & 7 & $8.32 \pm 1.10$ & $6.95 \pm 0.25$ \\
\hline 5 & GE0:GSE28364 & Italy & CRC & GPL13328 & 40 & 40 & $8.33 \pm 1.42$ & $11.01 \pm 1.15$ \\
\hline 6 & GE0:GSE35834 & Italy & CRC & GPL8786 & 55 & 23 & $4.32 \pm 1.57$ & $2.39 \pm 0.74$ \\
\hline 7 & GE0:GSE35982 & China & CRC & GPL4133 & 8 & 8 & $7.72 \pm 1.48$ & $5.11 \pm 0.43$ \\
\hline 8 & GE0:GSE49246 & China & CRC & GPL17496 & 40 & 40 & $9.51 \pm 0.32$ & $9.51 \pm 0.32$ \\
\hline 9 & GE0:GSE54088 & Germany & CRC & GPL8178 & 9 & 10 & $12.68 \pm 0.80$ & $11.70 \pm 0.83$ \\
\hline 10 & GE0:GSE54632 & China & CRC & GPL8786 & 5 & 5 & $4.08 \pm 0.13$ & $3.97 \pm 0.13$ \\
\hline 11 & GE0:GSE68377 & China & CRC & GPL8786 & 7 & 7 & $3.99 \pm 0.16$ & $4.00 \pm 0.16$ \\
\hline 12 & GE0:GSE83924 & Hungary & CRC & GPL16384 & 20 & 20 & $7.60 \pm 0.87$ & $6.26 \pm 0.55$ \\
\hline 13 & GE0:GSE98406 & USA & CRC & GPL16384 & 14 & 14 & $5.66 \pm 0.31$ & $5.22 \pm 0.10$ \\
\hline 14 & GE0:GSE13937 & USA & ESCA & GPL8835 & 27 & 25 & $8.31 \pm 1.13$ & $7.94 \pm 1.17$ \\
\hline 15 & GE0:GSE26595 & South Korea & GC & GPL8179 & 60 & 8 & $9.89 \pm 1.36$ & $7.99 \pm 0.81$ \\
\hline 16 & GE0:GSE26645 & China & $\mathrm{GC}$ & GPL11487 & 4 & 4 & $2.37 \pm 0.65$ & $2.47 \pm 1.33$ \\
\hline 17 & GE0:GSE28700 & Taiwan & $\mathrm{GC}$ & GPL9081 & 20 & 20 & $2.37 \pm 1.52$ & $1.66 \pm 1.11$ \\
\hline 18 & GE0:GSE33743 & Portugal & $\mathrm{GC}$ & GPL14895 & 37 & 4 & $7.77 \pm 0.52$ & $7.26 \pm 0.34$ \\
\hline 19 & GE0:GSE54397 & South Korea & GC & GPL15159 & 16 & 16 & $6.07 \pm 2.39$ & $5.36 \pm 0.92$ \\
\hline 20 & GE0:GSE63121 & China & GC & GPL8786 & 15 & 15 & $2.61 \pm 0.42$ & $2.62 \pm 0.34$ \\
\hline 21 & GE0:GSE67354 & South Korea & GC & GPL19952 & 5 & 5 & $8.08 \pm 0.56$ & $8.38 \pm 1.04$ \\
\hline 22 & GE0:GSE32678 & USA & PC & GPL7723 & 25 & 7 & $5.51 \pm 1.42$ & $3.95 \pm 1.50$ \\
\hline 23 & GE0:GSE41369 & Italy & PC & GPL16142 & 9 & 9 & $6.50 \pm 0.75$ & $5.99 \pm 1.34$ \\
\hline 24 & GE0:GSE43796 & South Korea & $\mathrm{PC}$ & GPL15159 & 6 & 5 & $8.42 \pm 1.23$ & $6.65 \pm 0.52$ \\
\hline 25 & GE0:GSE60978 & Norway & PC & GPL15159 & 51 & 6 & $7.40 \pm 0.74$ & $6.27 \pm 1.04$ \\
\hline 26 & GE0:GSE62452 & USA & $\mathrm{PC}$ & GPL6244 & 69 & 61 & $2.70 \pm 0.67$ & $2.67 \pm 0.58$ \\
\hline 27 & GE0:GSE6857 & USA & $\mathrm{HCC}$ & GPL4700 & 238 & 241 & $9.83 \pm 0.86$ & $10.01 \pm 0.76$ \\
\hline 28 & GE0:GSE10694 & China & $\mathrm{HCC}$ & GPL6542 & 78 & 88 & $11.59 \pm 0.97$ & $10.68 \pm 0.14$ \\
\hline 29 & GE0:GSE12717 & USA & $\mathrm{HCC}$ & GPL7274 & 10 & 6 & $9.55 \pm 2.18$ & $4.78 \pm 1.40$ \\
\hline 30 & GE0:GSE21362 & Japan & $\mathrm{HCC}$ & GPL10312 & 73 & 73 & $7.10 \pm 1.85$ & $5.87 \pm 1.39$ \\
\hline 31 & ArrayExpress:E-MTAB-298 & None & CRC & A-MEXP-1738 & 12 & 4 & $8.60 \pm 1.15$ & $8.11 \pm 0.50$ \\
\hline 32 & ArrayExpress:E-MEXP-3515 & None & CRC & A-MEXP-1797 & 8 & 8 & $6.36 \pm 1.20$ & $7.28 \pm 0.74$ \\
\hline 33 & ArrayExpress:E-GEOD-35602 & Japan & CRC & GPL8227 & 17 & 8 & $4.99 \pm 1.39$ & $2.18 \pm 1.42$ \\
\hline 34 & ArrayExpress:E-GE0D-30454 & Spain & CRC & GPL8179 & 42 & 20 & $12.55 \pm 0.68$ & $12.27 \pm 0.21$ \\
\hline 35 & ArrayExpress:E-TABM-341 & USA & GC & A-MEXP-620 & 184 & 169 & $8.54 \pm 1.16$ & $7.90 \pm 1.09$ \\
\hline 36 & TCGA (2016) & USA & BTC & None & 36 & 9 & $8.21 \pm 1.27$ & $6.98 \pm 1.23$ \\
\hline 37 & TCGA (2016) & USA & CRC & None & 619 & 11 & $7.88 \pm 1.47$ & $3.66 \pm 1.34$ \\
\hline 38 & TCGA (2016) & USA & ESCA & None & 187 & 13 & $7.81 \pm 2.25$ & $5.14 \pm 1.46$ \\
\hline 39 & TCGA (2016) & USA & GC & None & 446 & 45 & $5.75 \pm 1.85$ & $5.20 \pm 1.46$ \\
\hline 40 & TCGA (2016) & USA & PC & None & 179 & 4 & $7.05 \pm 1.33$ & $6.84 \pm 1.67$ \\
\hline 41 & TCGA (2016) & USA & $\mathrm{HCC}$ & None & 364 & 50 & $8.88 \pm 2.04$ & $6.49 \pm 1.40$ \\
\hline
\end{tabular}

survival curves using Engauge Digitizer Version 4.1 (http://digitizer.sourceforge.net/) [17]; (3) calculated according to the expression level of miR-224-5p via Kaplan-Meier analysis. We estimated the pooled HR in digestive system cancers using Stata Version 12.0. When the pooled HR was greater than 1 and its 95\% CI did not contain a 1, the data suggested that increasing miR-224-5p levels predict poor survival.

Heterogeneity in the studies was assessed using the chi-square $\left(\mathrm{x}^{2}\right)$ test of Cochran's Q [18] and inconsistency index $\left(\mathrm{I}^{2}\right)$ [19], and a P-value less than 0.05 or $\mathrm{I}^{2}$ greater than $50 \%$ indicated significant heterogeneity in the study, and a random-effects model was applied. If the P-value was greater than 0.05 or $\mathrm{I}^{2}$ was less than $50 \%$, the fixed-effects model was selected. Subgroup analyses were applied to assess the origin of heterogeneity when significant heterogeneity existed.

Sensitivity analysis was used to evaluate the robustness of the pooled overall result by excluding studies one by one and comparing the pooled results of different models. Publication bias was estimated using Egger's and Begg's bias tests and visually represented by a funnel plot. A P-value less than 0.05 indicated statistically significant publication bias, and the trim and fill method was used to evaluate the number of missing studies and recalculate the pooled variables. All the results were performed using Stata version 12.0. 


\section{Results}

\section{MiR-224-5p expression levels in cancers of the digestive tract}

A total of 41 miRNA expression microarray datasets and RNA-seq data were identified in this study, and the characteristics are presented in Table 1. As shown in Fig. 2, upregulation of miR-224-5p was observed in the digestive cancer group compared with the

Fig. 2. Forest plot of datasets evaluating miR-224-5p expression between digestive system cancer groups and normal control groups (random-effects model).

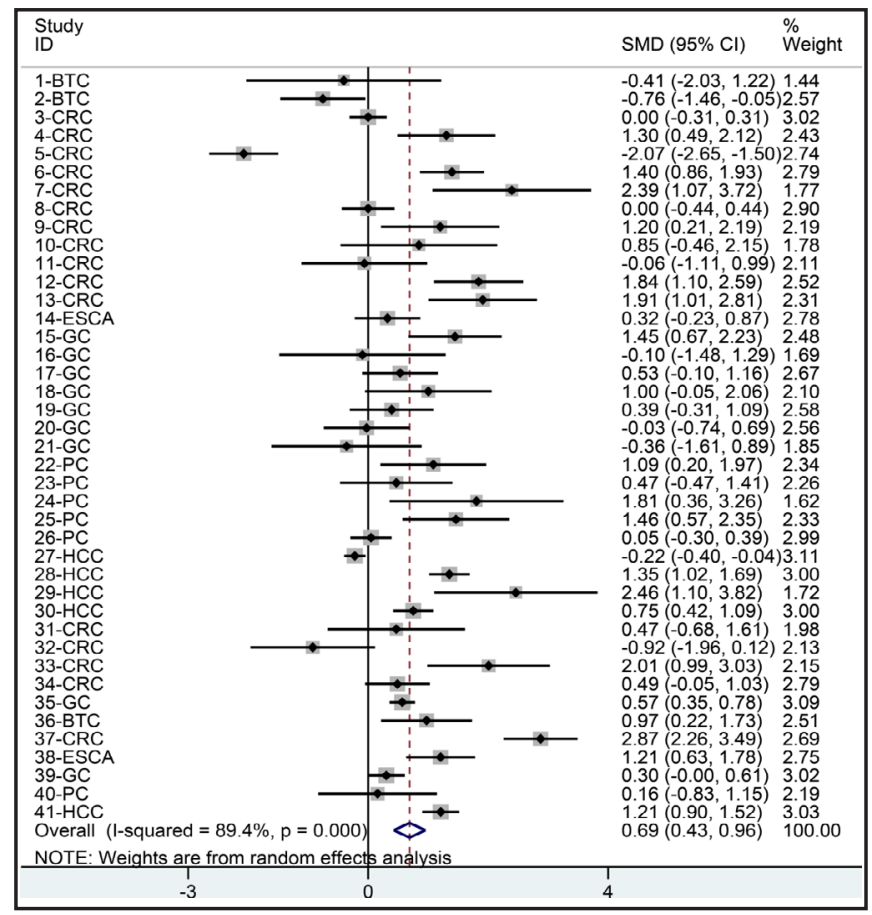

Fig. 3. The expression level of miR-224$5 p$ in CRC and GC. A. Forest plot of datasets evaluating miR-224-5p expression between CRC and normal control groups. B. Forest plot of datasets evaluating miR224-5p expression between GC and normal control groups.

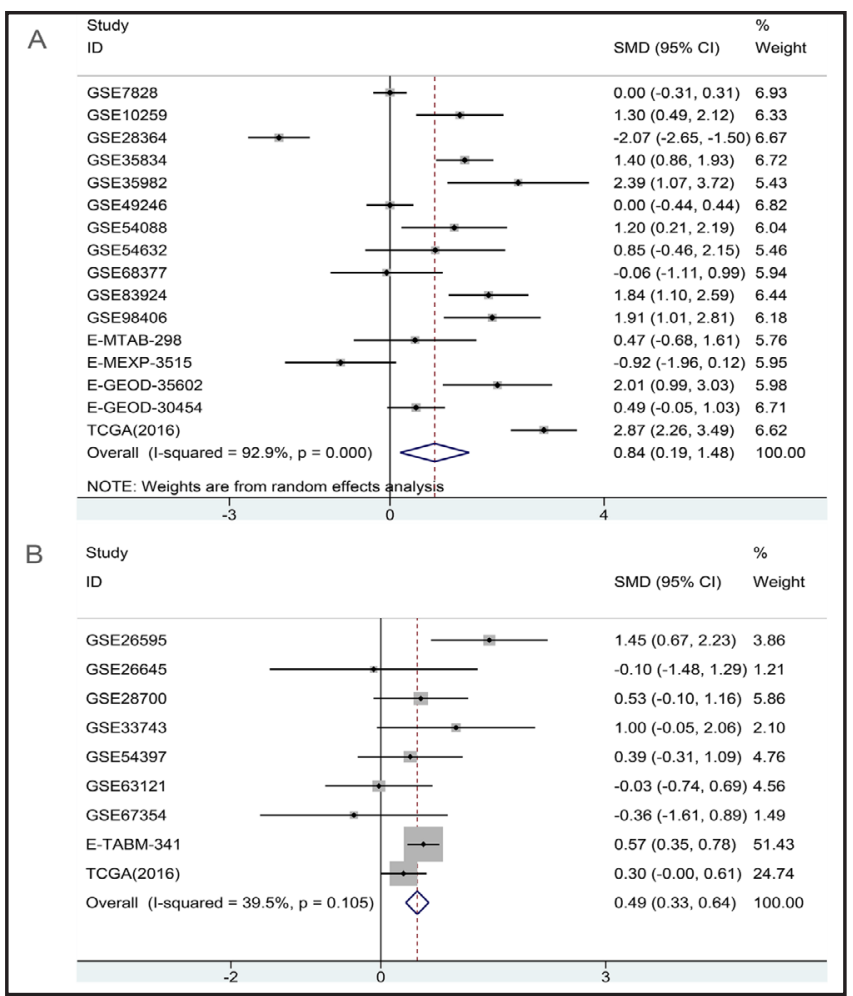


Fig. 4. The expression level of miR-224-5p in HCC and PC. A. Forest plot of datasets evaluating miR-224-5p expression between HCC and normal control groups. B. Forest plot of datasets evaluating miR-224-5p expression between PC and normal control groups.

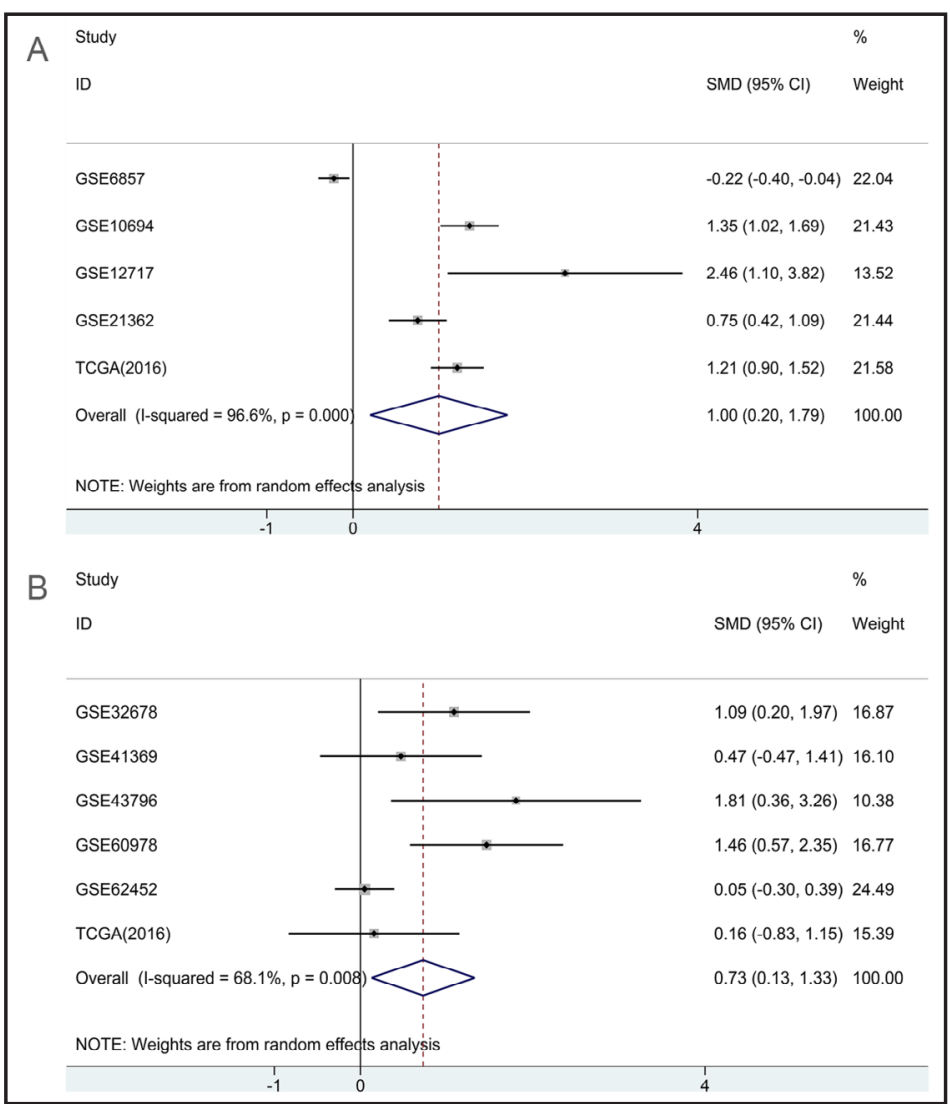

Fig. 5. The expression level of miR224-5p in BTC and ESCA. A. Forest plot of datasets evaluating miR-224$5 p$ expression between BTC and normal control groups. B. Forest plot of datasets evaluating miR-224-5p expression between ESCA and normal control groups.

normal control group, and the overall result was statistically significant $\quad(\mathrm{SMD}=0.69, \quad 95 \%$ CI: $\quad 0.43-0.96, \quad \mathrm{P}<0.0001)$. Significant heterogeneity occurred in individual datasets, so a random-effects model was applied (P heterogeneity $<0.0001$, $\mathrm{I}^{2}=89.4 \%$ ). $\quad$ Furthermore, subgroup analyses based on cancer type were constructed. Statistical significance was observed among four cancer types and their corresponding noncancerous groups, including

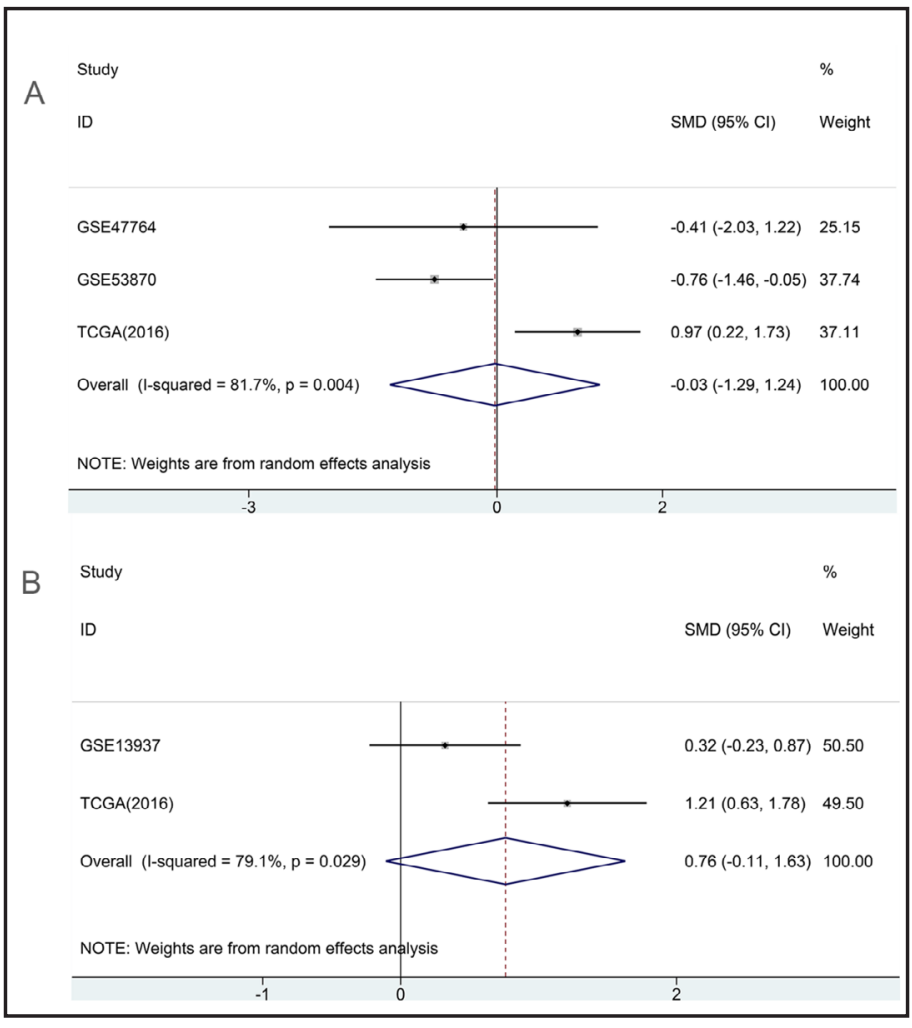

CRC ( $\mathrm{P}=0.011$; Fig. 3A), GC $(\mathrm{P}<0.0001$; Fig. 3B), HCC 
Fig. 6. Sensitivity analysis and publication bias test for the 41 included datasets. A. The results of the sensitivity analysis using a randomeffects model. B. Funnel plot of the 41 included datasets.

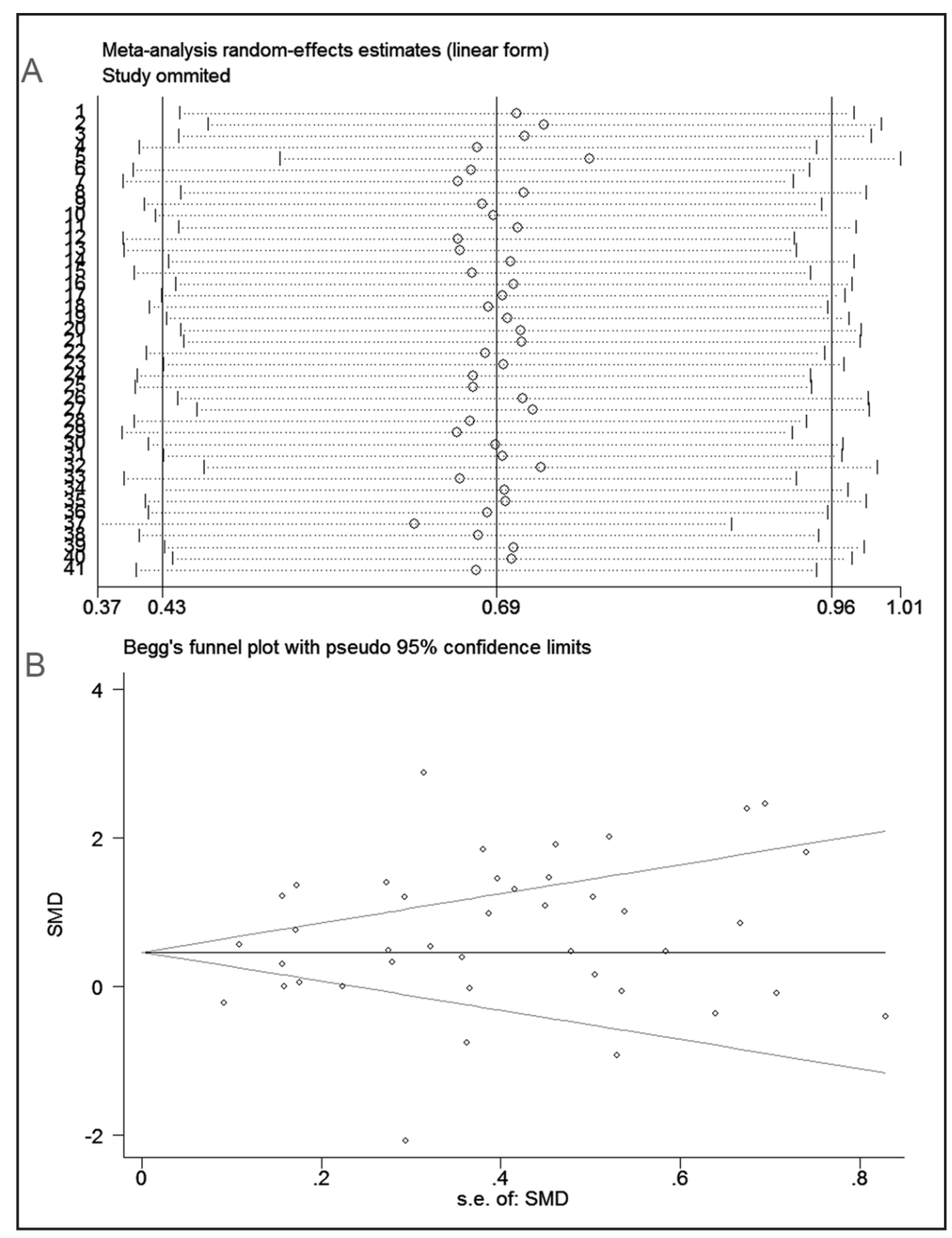

( $\mathrm{P}=0.014$; Fig. 4A), and $\mathrm{PC}(\mathrm{P}=0.017$; Fig. 4B). SMDs with 95\% CIs were 0.84 (0.19-1.48), 0.49 (0.33-0.64), $1.00(0.20-1.79)$, and $0.73(0.13-1.33)$, respectively. Regarding $\mathrm{BTC}(\mathrm{P}=0.969$; Fig. 5A) and ESCA ( $\mathrm{P}=0.086$; Fig. 5B), no statistical significance was observed between cancer and noncancerous groups, and SMDs with 95\% CIs were $-0.03(-1.29-1.24)$ and 0.76 (-0.11-1.63), respectively.

Next, sensitivity analysis was applied to estimate the robustness of the pooled SMD of miR-224-5p expression in all datasets. The results indicated that the pooled overall SMD was stable (Fig. 6A). P-values of Egger's and Begg's bias tests were 0.077 and 0.762, respectively, and the funnel plot was approximately symmetric (Fig. 6B), indicating that no publication bias existed regarding miR-224-5p expression.

\section{MiR-224-5p diagnostic value in cancers of the digestive tract}

To investigate the diagnostic value of miR-224-5p in cancers of the digestive tract, SROC curves and the AUCs with their 95\% CIs were analyzed in our study. The overall AUC of the including 41 datasets was 0.84 (95\% CI: 0.80-0.87) (Fig. 7). Next, we generated different SROC curves based on different cancer types. In SROC curves analyses of CRC, GC, HCC and PC, the AUCs with the 95\% CIs were 0.86 (0.82-0.88), 0.74 (0.70-0.78), 0.82 (0.78-0.85) and 
Fig. 7. SROC curve for digestive system cancer patients from normal controls based on miR224-5p expression.

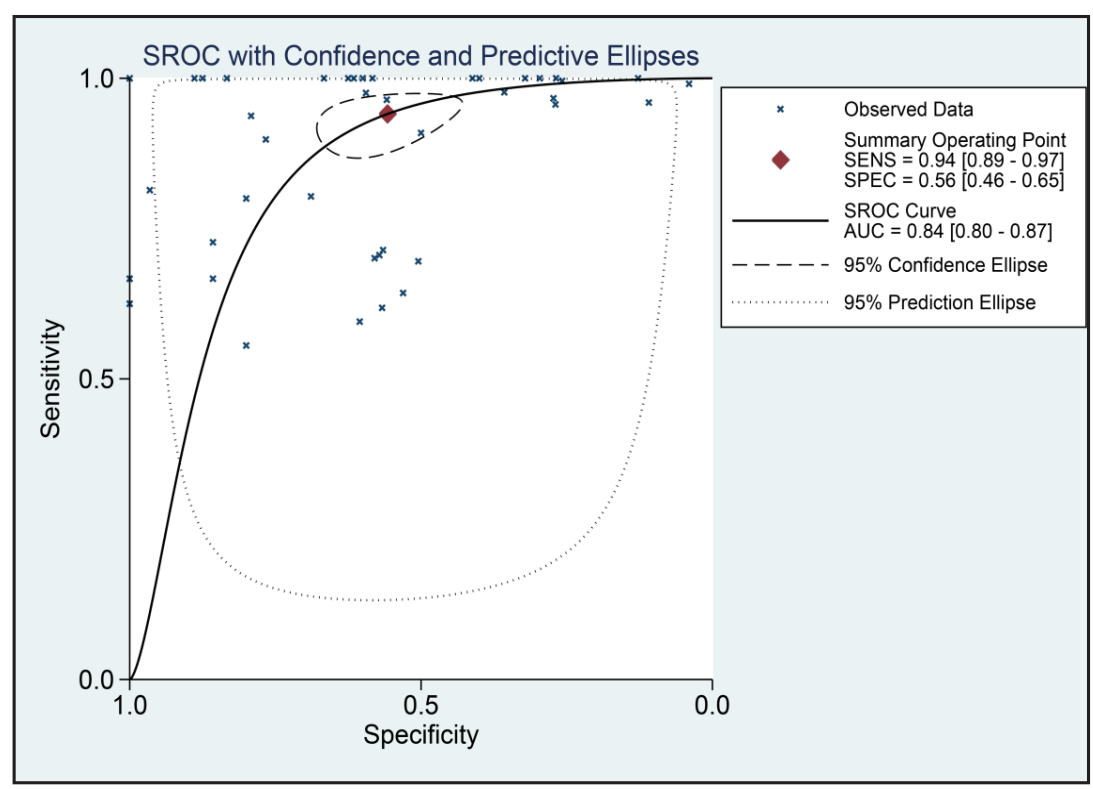

Fig. 8. SROC curves for CRC and GC patients from normal controls based on miR-224-5p expression. A. The diagnostic ability of miR-224-5p in CRC. B. The diagnostic ability of miR224-5p in GC.

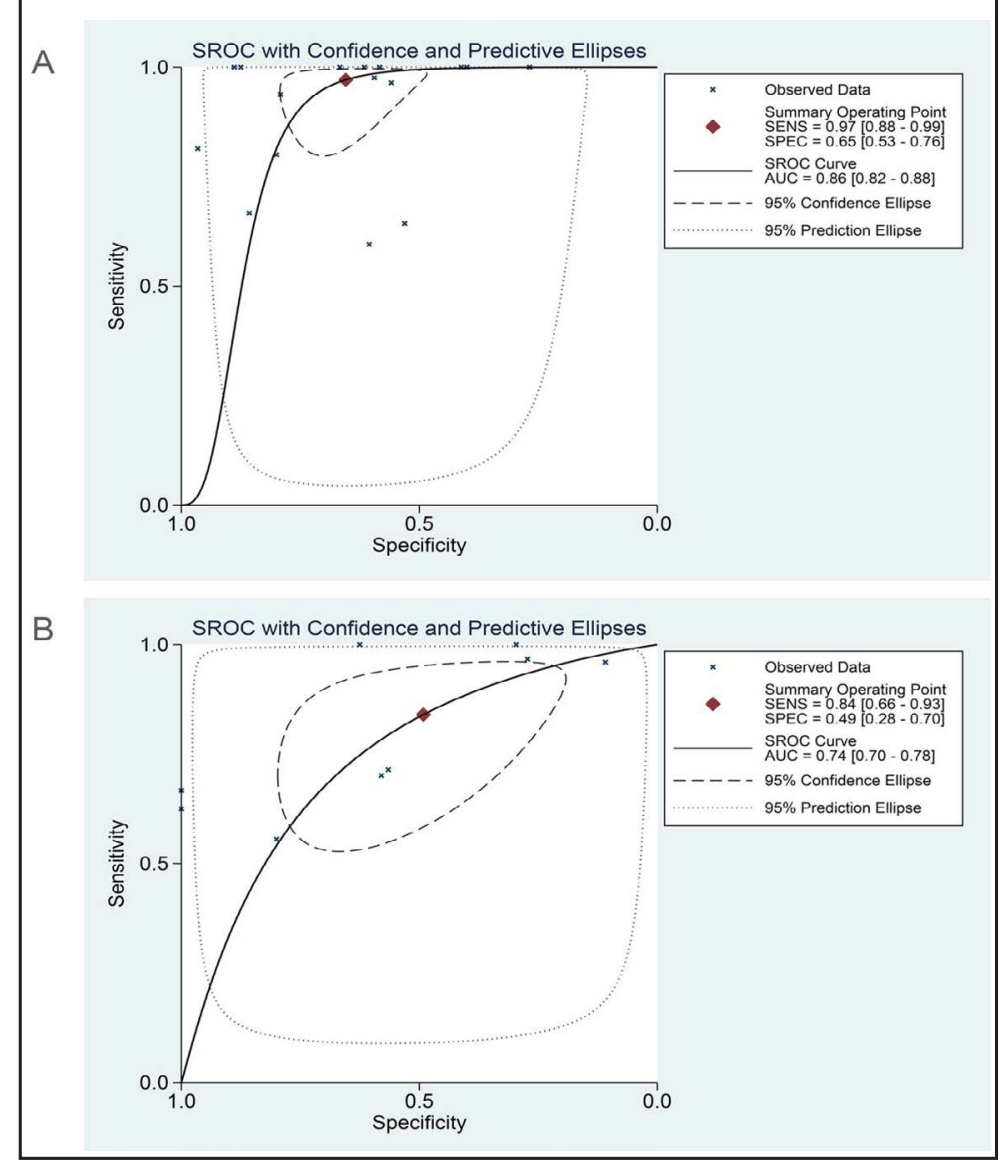

0.82 (0.79-0.85), respectively (Fig. 8A-8B, Fig. 9A-9B). Regarding BTC and ESCA, we did not perform SROC curve analysis given that the datasets only included three and two samples, respectively. 
Fig. 9. SROC curves for HCC and PC patients from normal controls based on miR-224-5p expression. A. The diagnostic ability of miR-224-5p in HCC. B. The diagnostic ability of miR-224-5p in PC.

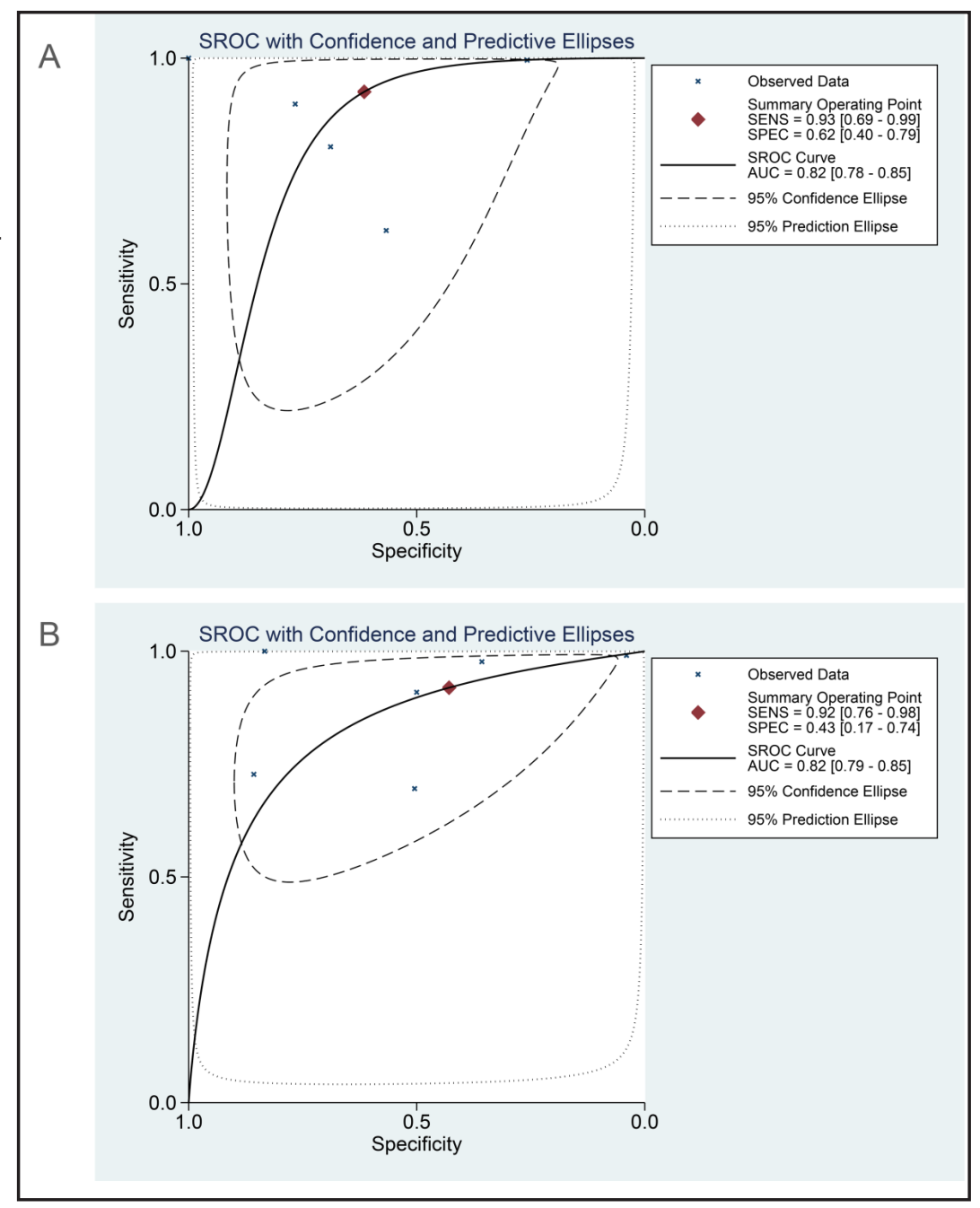

MiR-224-5p prognostic value in cancers of the digestive tract

To estimate miR-224-5p prognostic value in cancers of the digestive tract, the available data that exhibited miR-224-5p prognostic merit based on published studies, microarrays and RNA-seq data were collected. In total, 16 studies from 11 published manuscripts and two studies from two microarrays were included in this prognostic analysis. The characteristics of the included studies are presented in Table 2.

In the overall survival (OS) univariate analysis of 17 studies included from all 18 studies, the pooled HR and 95\% CI was 1.69 (1.15-2.49) ( $\mathrm{P}=0.007)$ (Fig. 10A), suggesting that increasing miR-224-5p levels predict unfavorable overall survival in patients with digestive system cancers. Simultaneously, in the OS multivariate analysis of eight studies selected from 18 studies, fixed-effects model results confirmed that increased miR-224-5p expression is associated with unfavorable overall survival in digestive system cancer patients (HR: 2.39, 95\% CI: 1.74-3.30, P<0.0001; Fig. 10B). However, progression-free survival (PFS) and diseasefree survival (DFS) analysis of six records assessed by both univariate and multivariate analyses revealed no statistically significant differences between miR-224-5p expression and PFS and DFS (HR: 1.07, 95\% CI: 0.38-3.02, P=0.893; Fig. 10C). Furthermore, we performed subgroup analyses based on cancer type of the pooled OS analysis, including 25 records, using both univariate and multivariate analyses. As shown in Fig. 11, elevated miR-224-5p expression predicts poor overall survival in CRC, and the result was statistically significant (HR: 2.52, 95\% CI: 1.80-3.53, P<0.0001). Nevertheless, no statistically significant differences were observed between miR-224-5p expression levels and the prognosis of patients with 
Table 2. Characteristics of included studies in the prognostic analysis of miR-224-5p. GC: gastric cancer; CRC: colorectal cancer; HCC: hepatocellular carcinoma; BTC: biliary tract cancer; ESCA: esophageal cancer; OS: overall survival; DFS: disease-free survival; PFS: progression-free survival; SC: survival curve; HR: hazard ratio; 95\% CI: 95\% confidence interval; U: univariate analysis; M: multivariate analysis

\begin{tabular}{|c|c|c|c|c|c|c|}
\hline $\begin{array}{l}\text { First author } \\
\text { (publication year) }\end{array}$ & Country & $\begin{array}{c}\text { Cancer } \\
\text { type }\end{array}$ & $\begin{array}{c}\text { Test } \\
\text { method }\end{array}$ & $\begin{array}{l}\text { Sample } \\
\text { size }\end{array}$ & $\begin{array}{c}\text { Analysis } \\
\text { method }\end{array}$ & $\operatorname{HR}(95 \% \mathrm{CI})$ \\
\hline Zhang Y et al(2016) & China & GC & qRT-PCR & 160 & SC & $\mathrm{OS}(\mathrm{U}) 0.83$ (0.28 to 2.44$)$ \\
\hline Smid D et al(2016) & Czech & GC & qRT-PCR & 41 & $\mathrm{SC}$ & $\mathrm{OS}(\mathrm{U}) 2.03(0.80$ to 5.14$)$ \\
\hline Shao CM et al(2012) & China & GC & ISH & 112 & $\mathrm{SC}$ & $\mathrm{OS}(\mathrm{U}) 2.54$ (1.38 to 4.68$)$ \\
\hline \multirow[t]{6}{*}{ Ling H et al(2015) } & Italy set 1 & CRC & qRT-PCR & 54 & Report & OS (U/M) 3.32 (1.15 to 9.59$) / 2.77$ (0.95 to 8.105$)$ \\
\hline & Italy set 2 & & qRT-PCR & 68 & Report & OS (U/M) 4.41 (1.03 to 18.84$) / 4.14$ ( 0.96 to 17.76$)$ \\
\hline & UK & & qRT-PCR & 41 & Report & OS (U) 4.92 (1.31 to 18.46$)$ \\
\hline & Romania & & qRT-PCR & 38 & Report & OS (U/M) 4.25 (1.01 to 18.89$) / 1.76(0.36$ to 8.64$)$ \\
\hline & Austria & & qRT-PCR & 74 & Report & $\mathrm{OS}(\mathrm{U} / \mathrm{M}) 2.14(1.21$ to 3.77$) / 2.36(1.32$ to 4.21$)$ \\
\hline & USA & & RNA-seq & 143 & Report & OS (U/M) 2.99 (1.08 to 8.23 ) / 2.88 (0.97 to 8.56$)$ \\
\hline Adamopoulos PG et al(2015) & Greece & CRC & qRT-PCR & 115 & Report & $\begin{array}{c}\text { OS (U/M) } 4.08(1.68 \text { to } 9.88) / 4.41(1.72 \text { to } 11.34) \\
\text { DFS (U/M) } 3.52(1.20 \text { to } 10.33) / 4.61(1.41 \text { to } 15.09)\end{array}$ \\
\hline Zhang GJ et al(2013) & China & CRC & qRT-PCR & 108 & $\mathrm{SC}$ & DFS (U) 2.04 (0.63 to 6.58$)$ \\
\hline Liao WT et al(2013) & China & CRC & qRT-PCR & 110 & SC & OS (U) 1.90 (0.92 to 3.89$)$ \\
\hline Yuan $\mathrm{K}$ et al(2013) & USA & CRC & qRT-PCR & 108 & SC & $\begin{array}{l}\text { OS (U) } 0.61(0.33 \text { to } 1.12) \\
\text { DFS (U) } 0.64(0.23 \text { to } 1.78)\end{array}$ \\
\hline Gyongyosi B et al(2014) & Italy & HCC & qRT-PCR & 20 & Report & $\begin{array}{c}\text { OS (U/M) } 0.24(0.07 \text { to } 0.79) / 0.11(0.013 \text { to } 0.913) \\
\text { PFS }(\mathrm{U} / \mathrm{M}) 0.28(0.09 \text { to } 0.92) / 0.125(0.015 \text { to } 1.034)\end{array}$ \\
\hline Liu M et al(2014) & China & HCC & qRT-PCR & 136 & Report & OS $(U) 0.700(0.553$ to 0.886$)$ \\
\hline Zhuang LP et al(2015) & China & HCC & qRT-PCR & 182 & Report & OS (U/M) 2.188 (1.264 to 3.786$) / 2.085$ (1.142 to 3.807$)$ \\
\hline Zhang $M$ et al(2015) & China & BTC & Microarray & 63 & Calculation & $\mathrm{OS}(\mathrm{U}) 1.01$ (0.53 to 1.91$)$ \\
\hline Mathe EA et al(2009) & USA & ESCA & Microarray & 27 & Calculation & $\mathrm{OS}(\mathrm{U}) 1.43(0.54$ to 3.82$)$ \\
\hline
\end{tabular}

GC (HR: 1.83, 95\% CI: 0.99-3.37, P=0.052) and HCC (HR: 0.84, 95\% CI: 0.38-1.86, P=0.666). Regarding BTC and ESCA, only one available study was included in the present investigation to discover the prognostic value of miR-224-5p. The HRs with 95\% CIs were 1.01 (0.53-1.91) $(\mathrm{P}=0.976)$ and $1.43(0.54-3.82)(\mathrm{P}=0.474)$, respectively.

Moreover, sensitivity analysis was performed with all 25 records of OS univariate and multivariate analyses, and the pooled HRs were not significantly altered, indicating the stability of the result (Fig. 12A). In the publication bias analysis, no significant indication of publication bias was observed with Begg's test $(\mathrm{P}=0.528)$, whereas Egger's test revealed a potential publication bias $(\mathrm{P}=0.007)$. After performing the trim and fill method, four missing studies were identified, but the newly pooled result (HR: 1.62, 95\% CI: 1.20-2.19) only minimally changed from the original result (HR: 1.84, 95\% CI: 1.33-2.54), indicating that the original result was minimally affected by publication bias. The funnel plot after performing the trim and fill method is presented in Fig. 12B.

\section{Potential target $m R N A$ s of miR-224-5p}

Potential target mRNAs of miR-224-5p were predicted using 12 existing miRNA-target prediction programs as described. Only genes that were simultaneously predicted by at least eight prediction solutions were selected. Accordingly, 388 mRNAs were recognized as potential target mRNAs of miR-224-5p for further analysis.

\section{GO annotation and KEGG pathway enrichment analysis}

GO annotation and KEGG pathway enrichment analysis of the 388 mRNAs were constructed using DAVID. The results of GO annotation enrichment analysis are summarized in Table 3-5 and Fig. 13. Regarding BP term annotation, the potential target mRNAs of miR-224-5p focused on a series of biological processes involved in development and transcription $(\mathrm{P}<0.001)$. Regarding $\mathrm{CC}$ term annotation, the target genes were significantly enriched in the neuron, cell, organelle, intracellular and somatodendritic compartments $(\mathrm{P}<0.001)$. Regarding MF term annotation, the target genes significantly altered the activity of transcriptional activators, protein kinases, phosphotransferases and protein serine/ threonine kinases, and the binding of protein, DNA, heterocyclic compounds and organic 
Fig. 10. Forest Plots estimated the prognostic value of miR-224-5p in digestive system cancers. A. Association between miR-224-5p overexpression and overall survival based on univariate analysis. B. Association between miR-224-5p overexpression and overall survival based on multivariate analysis. C. Association between miR-224-5p overexpression and disease-free survival and progression-free survival based on both univariate and multivariate analyses.

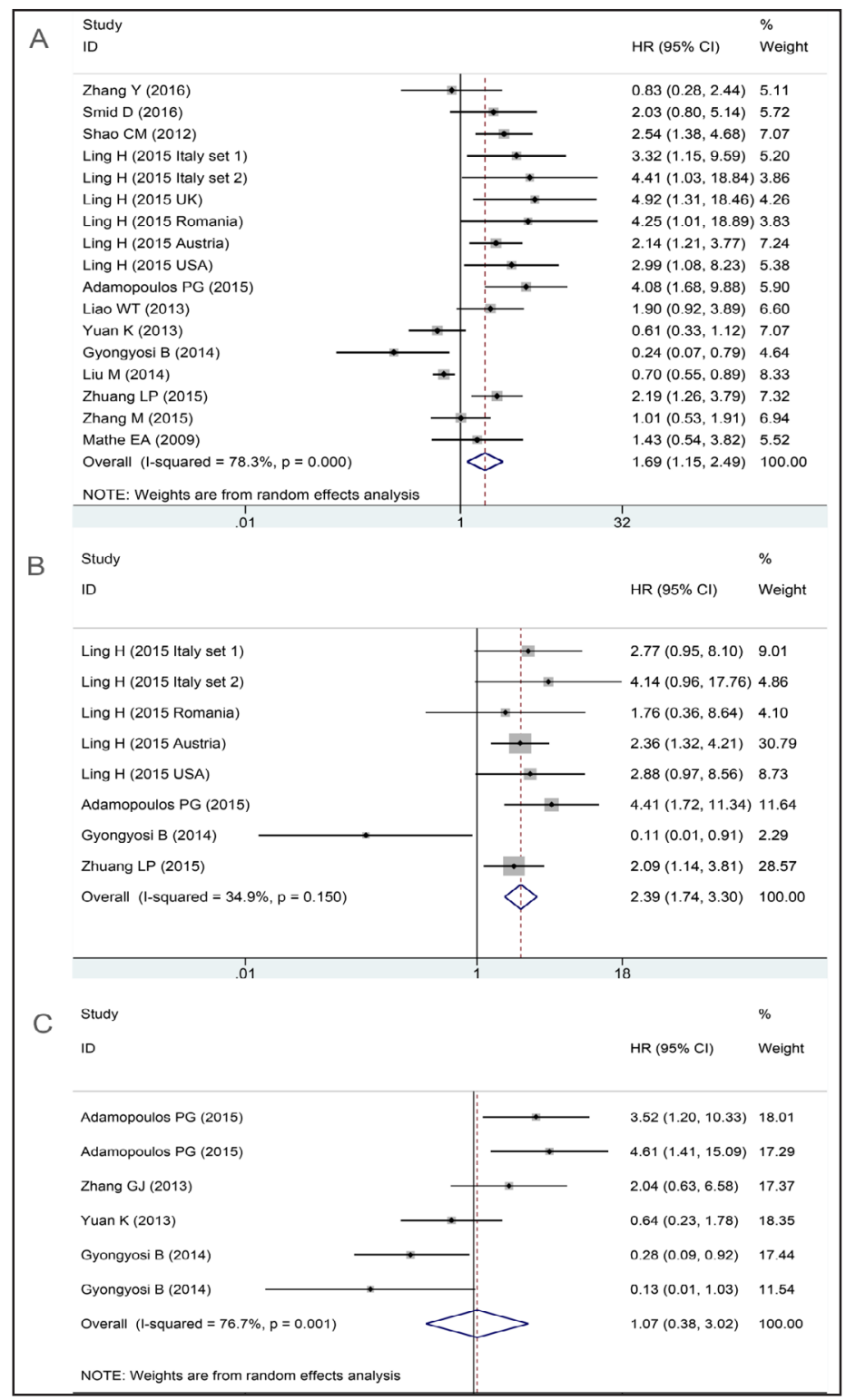

cyclic compounds $(\mathrm{P}<0.001)$. In KEGG pathway enrichment analysis, the results were chiefly concentrated in proximal tubule bicarbonate reclamation, ubiquitin-mediated proteolysis, PI3K-Akt signaling pathway, glioma, axon guidance, aldosterone-regulated sodium reabsorption, bile secretion and measles $(\mathrm{P}<0.05$, Table 6 and Fig. 14).

\section{Discussion}

MiRNAs play vital roles in various human cancers and participate in several biological processes, such as cell differentiation, proliferation, mobility, and survival [20]. In addition, miRNAs are involved in tumorigenesis and progression of malignancies via different mechanisms, including control of cell cycle [21, 22], apoptosis [23, 24], autophagy [25], epithelial-mesenchymal transition [26], drug resistance [27] and metabolic reprogramming [28]. All of the above data indicate that miRNAs have the potential to be novel diagnostic and prognostic biomarkers for malignant tumors. 
Fig. 11. Subgroup analysis by cancer type evaluated the association between miR-224-5p overexpression and overall survival based on both univariate and multivariate analyses.

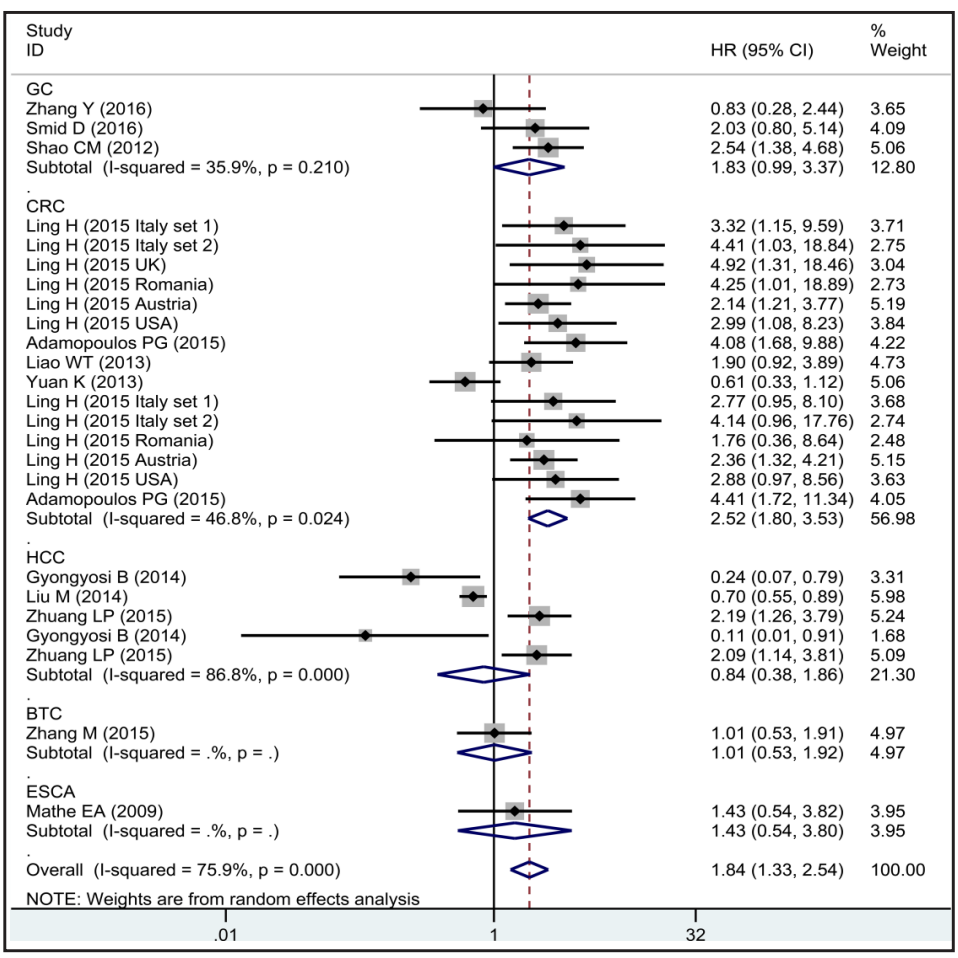

Fig. 12. Sensitivity analysis and publication bias test for all 25 records of overall survival based on both univariate and multivariate analyses. A. The results of the sensitivity analysis based on a randomeffects model. B. Funnel plot after performing the trim and fill method for the included studies.

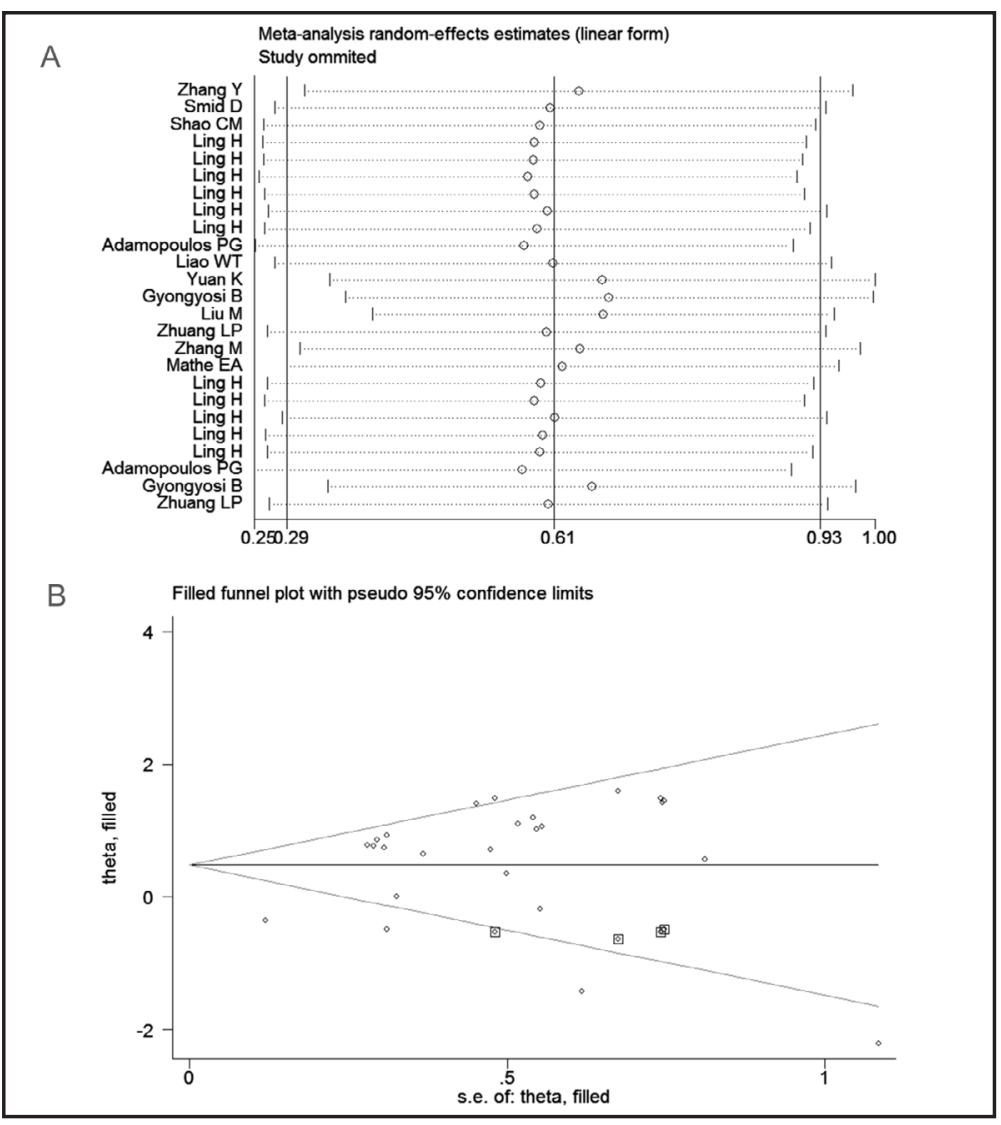

Increasing evidence demonstrates that miR-224 may be involved in the tumorigenesis and progression of various malignant tumors and participate in several biological processes. 
Table 3. GO enrichment analysis (Biological Process) of the potential miR-224-5p target mRNAs constructed by DAVID

\begin{tabular}{|c|c|c|c|c|}
\hline Biobgical Process & term & Count & P-value & Genes \\
\hline GOTERM_BP_ALL & G0:0048731 system development & 134 & $\begin{array}{l}3.77 \mathrm{E}- \\
08\end{array}$ & $\begin{array}{l}\text { GLDN, HMGCR, F2RL1, GDF5, MEGF11, HOXD10, SERPINE1, RNF38, } \\
\text { RALA, LRRC55, etc. }\end{array}$ \\
\hline GOTERM_BP_ALL & G0:0007275 multicellular organism development & 144 & $\begin{array}{c}2.99 \mathrm{E}- \\
07\end{array}$ & $\begin{array}{l}\text { GLDN, HMGCR, F2RL1, GDF5, PRTG, MEGF11, H0XD10, SERPINE1, } \\
\text { RNF38, RALA, etc. }\end{array}$ \\
\hline GOTERM_BP_ALL & G0:0048468 cell devebpment & 73 & $\begin{array}{c}5.24 \mathrm{E}- \\
07\end{array}$ & $\begin{array}{l}\text { GLDN, F2RL1, WASF2, GDF5, NCS1, KCNJ10, SDC4, H0XD10, TMF1, } \\
\text { SPRY3, etc. }\end{array}$ \\
\hline GOTERM_BP_ALL & G0:0048856 anatomical structure development & 156 & $\begin{array}{c}6.11 \mathrm{E}- \\
07\end{array}$ & $\begin{array}{l}\text { GLDN, HMGCR, RP2, F2RL1, PRTG, GDF5, MEGF11, HOXD10, SERPINE1, } \\
\text { RNF38, etc. }\end{array}$ \\
\hline GOTERM_BP_ALL & G0:0007399 nervous system development & 78 & $\begin{array}{c}6.35 \mathrm{E}- \\
07\end{array}$ & $\begin{array}{l}\text { SLC5A3, GLDN, GDF5, NCS1, CXCR2, KCNJ10, SDC4, HOXD10, SPRY3, } \\
\text { SLC1A2, etc. }\end{array}$ \\
\hline GOTERM_BP_ALL & G0:0032502 developmental process & 159 & $\begin{array}{c}8.00 \mathrm{E}- \\
07\end{array}$ & $\begin{array}{l}\text { GLDN, HMGCR, RP2, F2RL1, PRTG, GDF5, MEGF11, HOXD10, SYP, } \\
\text { SERPINE1, etc. }\end{array}$ \\
\hline GOTERM_BP_ALL & $\begin{array}{l}\text { G0:0045944 positive regulation of transcription from RNA polymerase } \\
\text { II promoter }\end{array}$ & 46 & $\begin{array}{l}1.53 \mathrm{E}- \\
06\end{array}$ & $\begin{array}{l}\text { AKNA, ELF4, F2RL1, BMPR2, HOXD10, ATF2, NFATC2IP, TCF21, PAX9, } \\
\text { ASH2L, etc. }\end{array}$ \\
\hline
\end{tabular}

A number of studies have identified the aberrant expression of miR-224 in different types of neoplasm. For example, up-regulated miR-224 expression levels were noted in cervical cancer [9], ovarian cancer [8], breast cancer [29], lung cancer [30] and glioma [31]. In contrast, down-regulated miR-224 expression levels were discovered in prostate cancer [32], diffuse large B cell lymphoma [33], and meningioma [34]. Regarding the clinical value of miR-224 in digestive system cancers, Yu et al. [35] performed in situ hybridization to identify the expression level of miR-224 in samples from 130 HCC patients and found that miR-224 was significantly increased in HCC tissues compared with adjacent noncancerous liver tissues. Wang et al. [36] discovered a trend of miR-224 expression (HCC tissues> paired adjacent nontumorous liver > normal liver) based on $100 \mathrm{HCC}$ and paired adjacent nontumorous liver samples and 40 healthy liver tissues using qRT-PCR. Meanwhile, Adamopoulos et al. [37] identified the expression level of miR-224 in 115 CRC samples with 66 adjacent nontumor mucosae samples and observed significantly up-regulated miR-224 expression in CRC tissues compared with adjacent non-cancer mucosae. Liao et al. [38] found that miR-224 expression levels were significantly increased in 43 CRC samples compared with corresponding normal tissues via qRT-PCR. Simultaneously, He et al. [39] demonstrated that miR-224 was highly expressed in 29 GC samples compared with adjacent non-tumor tissues by qRT-PCR. Moreover, Mees et al. [40] verified significant overexpression of miR-224 in pancreatic ductal adenocarcinoma (PDAC) cell lines using microarray and qRT-PCR.

In the present study, we gathered a significant amount of data regarding miR-224-5p expression in digestive system cancers from GEO, ArrayExpress and TCGA public databases, including 41 microarray and RNA-seq datasets. Then, we performed a comprehensive metaanalysis of miR-224-5p expression data from all 41 microarray and RNA-seq datasets. The results indicated that miR-224-5p expression was significantly up-regulated in digestive system cancers compared with the noncancerous group. According to subgroup analyses based on cancer type, the up-regulated expression of miR-224-5p was verified in CRC, GC, HCC, and PC. The results were consistent with the previous studies mentioned above and were credible based on the large sample size in the study. However, no statistically significant differences in BTC and ESCA were observed. Considering that only three and two datasets were included in the analysis of BTC and ESCA, the stability of the pooled results is questionable. Therefore, further studies investigating miR-224-5p expression levels in BTC and ESCA are necessary to validate our conclusions.

Previous studies have suggested that miR-224 may be a prospective biomarker for the diagnosis of HCC [41-43]. Okajima et al. [44] performed a systematic review of microRNAs in plasma and identified miR-224 as a sensitive biomarker for detecting and monitoring HCC. However, the diagnostic value of miR-224-5p in the other digestive system cancers remains 
Table 4. GO enrichment analysis (Cellular Component) of the potential miR-224-5p target mRNAs constructed by DAVID

\begin{tabular}{|c|c|c|c|c|}
\hline $\begin{array}{l}\text { Cellular } \\
\text { Component }\end{array}$ & term & Count & P-value & Genes \\
\hline GOTERM_CC_ALL & GO:0097458 neuron part & 47 & $1.35 \mathrm{E}-04$ & $\begin{array}{l}\text { TNFRSF21, PHLPP2, SRSF10, AGFG1, } \\
\text { BMPR2, NCS1, IGF2BP1, KCNJ10, GABBR2, } \\
\text { ITSN1, etc. }\end{array}$ \\
\hline GOTERM_CC_ALL & GO:0044464 cell part & 343 & $1.48 \mathrm{E}-04$ & $\begin{array}{l}\text { DYNC1LI1, ATP1B3, GLDN, ATP1B2, } \\
\text { PITPNA, RP2, GDF5, MEGF11, WTAP, ITSN1, } \\
\text { etc. }\end{array}$ \\
\hline GOTERM_CC_ALL & GO:0043005 neuron projection & 37 & $1.77 \mathrm{E}-04$ & $\begin{array}{l}\text { TNFRSF21, SRSF10, BMPR2, NCS1, } \\
\text { IGF2BP1, GABBR2, ITSN1, HNRNPA3, SYP, } \\
\text { SLC1A2, etc. }\end{array}$ \\
\hline GOTERM_CC_ALL & GO:0005623 cell & 343 & $2.12 \mathrm{E}-04$ & $\begin{array}{l}\text { DYNC1LI1, ATP1B3, GLDN, ATP1B2, } \\
\text { PITPNA, RP2, GDF5, MEGF11, WTAP, ITSN1, } \\
\text { etc. }\end{array}$ \\
\hline GOTERM_CC_ALL & GO:0043226 organelle & 288 & $2.80 \mathrm{E}-04$ & $\begin{array}{l}\text { DYNC1LI1, ATP1B3, PITPNA, RP2, WTAP, } \\
\text { ITSN1, HOXD10, SSR1, MAP3K7, SYP, etc. }\end{array}$ \\
\hline GOTERM_CC_ALL & $\begin{array}{c}\text { GO:0043227 } \sim \text { membrane-bounded } \\
\text { organelle }\end{array}$ & 270 & $4.43 \mathrm{E}-04$ & $\begin{array}{l}\text { DYNC1LI1, ATP1B3, PITPNA, RP2, ITSN1, } \\
\text { WTAP, HOXD10, SSR1, MAP3K7, SYP, etc. }\end{array}$ \\
\hline GOTERM_CC_ALL & GO:0005622 intracellular & 305 & $5.90 \mathrm{E}-04$ & $\begin{array}{l}\text { DYNC1LI1, ATP1B3, ATP1B2, PITPNA, RP2, } \\
\text { GDF5, WTAP, ITSN1, HOXD10, SSR1, etc. }\end{array}$ \\
\hline GOTERM_CC_ALL & $\begin{array}{c}\text { GO:0036477 } \sim \text { somatodendritic } \\
\text { compartment }\end{array}$ & 27 & $6.67 \mathrm{E}-04$ & $\begin{array}{l}\text { AGFG1, SRSF10, BMPR2, NCS1, IGF2BP1, } \\
\text { ELOVL5, TRIM9, CAMK2D, INPP5F, } \\
\text { PAFAH1B1, etc. }\end{array}$ \\
\hline GOTERM_CC_ALL & GO:0044424 intracellular part & 298 & $8.70 \mathrm{E}-04$ & $\begin{array}{l}\text { DYNC1LI1, ATP1B3, ATP1B2, PITPNA, RP2, } \\
\text { WTAP, ITSN1, HOXD10, SSR1, MAP3K7, etc. }\end{array}$ \\
\hline GOTERM_CC_ALL & $\begin{array}{c}\text { GO:0043231 intracellularmembrane- } \\
\text { bounded organelle }\end{array}$ & 246 & $1.09 \mathrm{E}-03$ & $\begin{array}{l}\text { DYNC1LI1, ATP1B3, RP2, ITSN1, WTAP, } \\
\text { HOXD10, SSR1, SYP, MAP3K7, EPC2, etc. }\end{array}$ \\
\hline
\end{tabular}

Table 5. GO enrichment analysis (Molecular Function) of the potential miR-224-5p target mRNAs constructed by DAVID

\begin{tabular}{|c|c|c|c|c|}
\hline $\begin{array}{l}\text { Molecular } \\
\text { Function }\end{array}$ & term & Count & P-value & Genes \\
\hline GOTERM_MF_ALL & $\begin{array}{l}\text { G0:0001077 transcriptional activator activity, RNA polymerase II } \\
\text { core promoter proximal region sequence-specific binding }\end{array}$ & 19 & $1.60 \mathrm{E}-06$ & $\begin{array}{l}\text { AKNA, PLAG1, PHOX2B, EGR2, KLF13, ELF4, } \\
\text { SOX11, NR4A3, NPAS4, FOSB, etc. }\end{array}$ \\
\hline GOTERM_MF_ALL & $\begin{array}{l}\text { GO:0001228 transcriptional activator activity, RNA polymerase II } \\
\text { transcription regulatory region sequence-specific binding }\end{array}$ & 22 & $3.35 \mathrm{E}-06$ & $\begin{array}{l}\text { MAF, AKNA, MAFG, PLAG1, PHOX2B, EGR2, KLF13, } \\
\text { ELF4, SOX11, FOSB, etc. }\end{array}$ \\
\hline GOTERM_MF_ALL & $\begin{array}{l}\text { GO:0000982 transcription factor activity, RNA polymerase II core } \\
\text { promoter proximal region sequence-specific binding }\end{array}$ & 21 & $2.45 \mathrm{E}-05$ & $\begin{array}{l}\text { AKNA, PLAG1, PHOX2B, EGR2, KLF13, ELF4, } \\
\text { SOX11, NR4A3, NPAS4, FOSB, etc. }\end{array}$ \\
\hline GOTERM_MF_ALL & G0:0004672 protein kinase activity & 29 & $1.59 \mathrm{E}-04$ & $\begin{array}{l}\text { CDK19, PRPF4B, NUAK1, BMPR2, STK17A, TRIB1, } \\
\text { MAP3K7, IRAK3, PAK2, CAMK2D, etc. }\end{array}$ \\
\hline GOTERM_MF_ALL & G0:0005515 protein binding & 251 & $1.92 \mathrm{E}-04$ & $\begin{array}{l}\text { DYNC1LI1, ATP1B3, GLDN, ATP1B2, RP2, GDF5, } \\
\text { UHRF1BP1, ITSN1, WTAP, SSR1, etc. }\end{array}$ \\
\hline GOTERM_MF_ALL & $\begin{array}{l}\text { G0:0016773 phosphotransferase activity, alcohol group as } \\
\text { acceptor }\end{array}$ & 32 & $3.05 \mathrm{E}-04$ & $\begin{array}{l}\text { CDK19, PRPF4B, NUAK1, BMPR2, STK17A, TRIB1, } \\
\text { MAP3K7, IRAK3, PAK2, CAMK2D, etc. }\end{array}$ \\
\hline GOTERM_MF_ALL & $\begin{array}{c}\text { GO:0000978 RNA polymerase II core promoter proximal region } \\
\text { sequence-specific DNA binding }\end{array}$ & 19 & $3.66 \mathrm{E}-04$ & $\begin{array}{l}\text { AKNA, PLAG1, PHOX2B, EGR2, KLF13, ELF4, FOSB, } \\
\text { NR4A3, NPAS4, MBD2, etc. }\end{array}$ \\
\hline GOTERM_MF_ALL & GO:0004674 protein serine/threonine kinase activity & 22 & $3.89 \mathrm{E}-04$ & $\begin{array}{l}\text { CDK19, PIK3CG, PRPF4B, NUAK1, TAOK1, BMPR2, } \\
\text { CDK9, CDK6, STK17A, MAP3K7, etc. }\end{array}$ \\
\hline GOTERM_MF_ALL & GO:1901363 heterocyclic compound binding & 152 & 4.36E-04 & $\begin{array}{l}\text { CAST, AKNA, DYNC1LI1, GNA14, PRPF4B, HMGCR, } \\
\text { RP2, HBS1L, HOXD10, MAP3K7, etc. }\end{array}$ \\
\hline GOTERM_MF_ALL & GO:0097159 organic cyclic compound binding & 153 & $5.78 \mathrm{E}-04$ & $\begin{array}{l}\text { CAST, AKNA, DYNC1LI1, GNA14, PRPF4B, HMGCR, } \\
\text { RP2, HBS1L, HOXD10, SYP, etc. }\end{array}$ \\
\hline
\end{tabular}

Table 6. KEGG pathway enrichment analysis of the potential miR-224-5p target mRNAs constructed by DAVID

\begin{tabular}{lcccc}
\hline Category & term & Count & P-value & Genes \\
\hline KEGG pathway & hsa04964:Proximal tubule bicarbonate reclamation & 4 & $1.01 \mathrm{E}-02$ & ATP1B3, ATP1B2, GLS, SLC4A4 \\
KEGG_PATHWAY & hsa04120:Ubiquitin mediated proteolysis & 8 & $1.88 \mathrm{E}-02$ & ANAPC1, TRIM37, UBE2D3, UBE2G1, UBA2, UBE2J1, NEDD4L, BRCA1 \\
KEGG_PATHWAY & hsa04151:PI3K-Akt signaling pathway & 14 & $1.89 \mathrm{E}-02$ & PPP2R1B, PIK3CG, PHLPP1, PHLPP2, CDK6, BRCA1, ATF2, NRAS, LPAR5, PRLR, etc. \\
KEGG_PATHWAY & hsa05214:Glioma & 5 & $3.95 \mathrm{E}-02$ & PIK3CG, NRAS, PDGFRA, CAMK2D, CDK6 \\
KEGG_PATHWAY & hsa04360:Axon guidance & 7 & $4.00 \mathrm{E}-02$ & NRAS, PAK2, EFNB3, GSK3B, DPYSL5, DPYSL2, ARHGEF12 \\
KEGG_PATHWAY & 4 & $4.15 \mathrm{E}-02$ & PIK3CG, ATP1B3, ATP1B2, NEDD4L \\
KEGG_PATHWAY & hsa04960:Aldosterone-regulated sodium reabsorption & 4 & ATP1B3, ATP1B2, HMGCR, SLC4A4, SLC10A2 \\
KEGG_PATHWAY & hsa04976:Bile secretion & 5 & $4.75 \mathrm{E}-02$ & MAP3K7, PIK3CG, TACR1, GSK3B, CDK6, ADAR, CD28 \\
KEGG_PATHWAY & hsa05162:Measles & 7 & $4.83 \mathrm{E}-02$ &
\end{tabular}

unclear to date. In the present study, we performed systemic and integrated research to reveal the prospective diagnostic merit of miR-224-5p. The results indicated that miR224-5p exhibited moderate diagnostic ability (AUC $=0.84,95 \%$ CI: 0.80-0.87) of digestive system cancers. In subgroup analyses based on cancer type, the AUCs with the 95\% CIs 
Fig. 13. Top ten GO enrichment analysis terms of potential miR-224-5p target genes identified by DAVID.

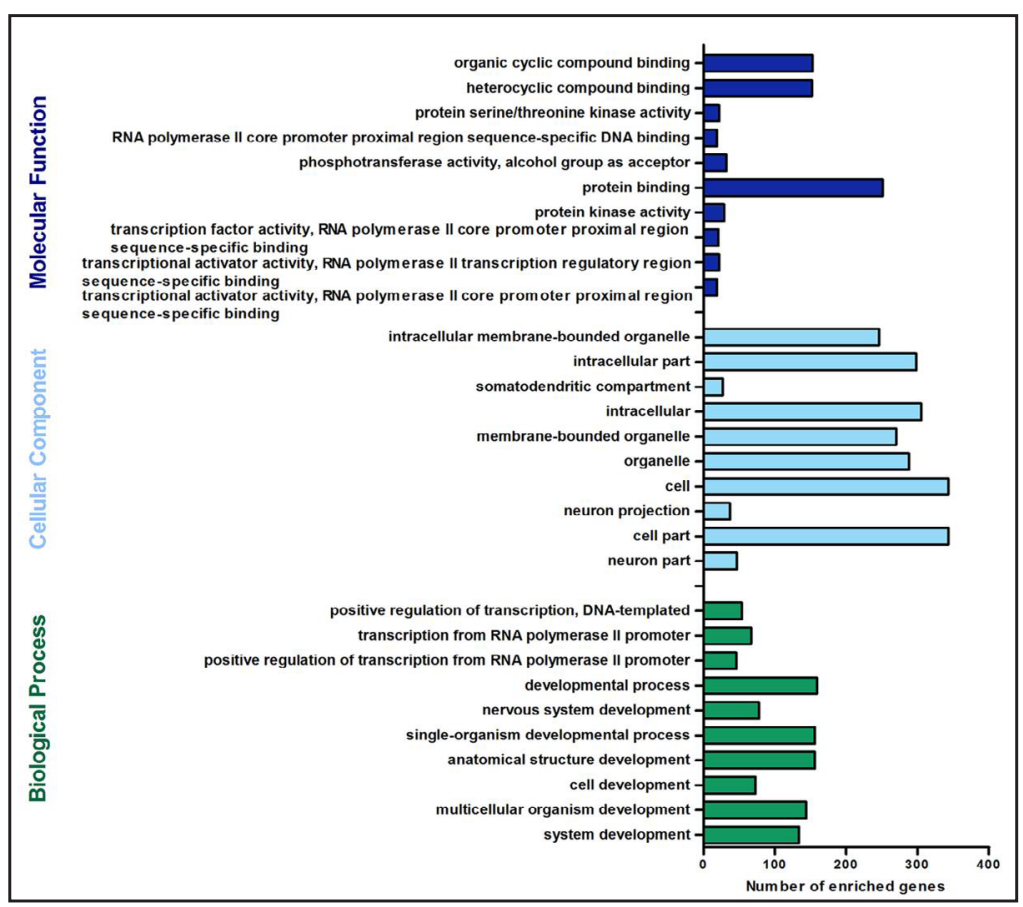

Fig. 14. The statistically significant KEGG pathways of potential miR-224-5p target genes identified by DAVID.

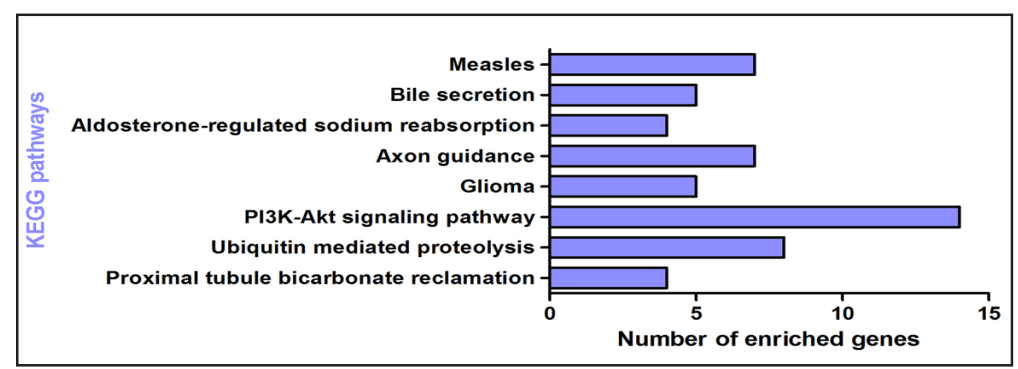

were $0.86(0.82-0.88), 0.74(0.70-0.78), 0.82(0.78-0.85)$ and $0.82(0.79-0.85)$ in CRC, GC, HCC and PC, respectively. We took advantage of the large sample size in this study when drawing conclusions about the diagnostic merit of miR-224-5p in digestive system cancers. Nevertheless, the detection precision of high-throughput technology, including microarray analysis and RNA sequencing, may be less precise than qRT-PCR methods. Therefore, further researches based on qRT-PCR are necessary for exploring the diagnostic capability of miR224-5p.

A previous review reported by Chen et al. [45] demonstrated that miR-224 may be a potential therapeutic target for malignant tumors via targeting associated genes and pathways. In our study, we conducted a meta-analysis including 16 studies from the literature and two studies from microarrays to quantitatively estimate the prognostic capability of miR-224-5p. In the OS univariate and multivariate analyses, the pooled HRs and $95 \%$ CIs were $1.69(1.15-2.49)(\mathrm{P}=0.007)$ and $2.39(1.74-3.30)(\mathrm{P}<0.0001)$, suggesting that increased miR-224-5p expression predicts poor overall survival in patients with digestive system cancers. Subgroup analyses suggested that miR-224-5p might be a prospectively prognostic biomarker for patients with CRC (HR: 2.52, 95\% CI: 1.80-3.53, P<0.0001). Three and five eligible studies were included in the prognostic analyses of GC and HCC patients, respectively. However, only one study was available that reported the prognostic merit of miR-224-5p in patients with both BTC and ESCA. No eligible study is available on the prognostic performance of miR-224-5p in PC patients. Thus, the reliability of some of our results remains inadequate due to the number of included studies. More studies are required 
to explore the prognostic merit of miR-224-5p in patients with different types of digestive system cancers.

MiR-224 targets several important genes and pathways in the tumorigenesis and progression of malignant tumors, such as mTOR, Wnt/ $\beta$-catenin signaling, KRAS, and SMAD4 $[13,14,46,47]$. To reveal the potential target mRNAs and pathways of miR-224-5p, we used bioinformatics methods that can supplement the limitations of experimental time and cost. The results revealed that 388 potential target mRNAs of miR-224-5p were predicted by 12 existing miRNA-target prediction programs and were simultaneously predicted by at least eight prediction solutions. Then, we performed GO annotation and KEGG pathway enrichment analysis of the 388 mRNAs using DAVID. Among GO annotation enrichment analysis of the miR-224-5p target mRNAs, biological process development and transcription were the most enriched terms in BP term annotation. In addition, neuron, cell, organelle, intracellular and somatodendritic compartments were significantly identified in CC term annotation. In MF term annotation, the target genes were significantly focused on the activity of transcriptional activators, protein kinases, phosphotransferases and protein serine/threonine kinases, as well as the binding of protein, DNA, heterocyclic compounds and organic cyclic compounds. In the KEGG pathway enrichment analysis of miR-224-5p target genes, eight pathways were identified, including proximal tubule bicarbonate reclamation, ubiquitin-mediated proteolysis, PI3K-Akt signaling pathway, glioma, axon guidance, aldosterone-regulated sodium reabsorption, bile secretion and measles. All the results demonstrated that miR-224$5 \mathrm{p}$ may affect the tumorigenesis and progression of malignant tumors by targeting multiple genes and signaling pathways. The inter-connections of "miRNA-mRNA-function" are known as miRNAs involved in the post-transcriptional regulation of genes by inducing degradation or repressing translation and regulating numerous genes associated with different biological processes. In our study, 388 mRNAs were identified using bioinformatics methods. The inter-connections between these newly identified targets and functions were discovered by performing GO annotation and KEGG pathway enrichment analysis. Some of the results are consistent with previously published studies, whereas others must be experimentally verified. Hence, further studies are essential to validate our findings.

Some limitations in several aspects of the study should be noted. First, in the analyses of the clinical value of miR-224-5p, heterogeneity of the pooled SMDs and pooled HRs was inevitable for a number of reasons, such as diverse databases from which the expression profiles were acquired, and different methods used for HR extraction. When a P-value was less than 0.05 or $\mathrm{I}^{2}$ was greater than $50 \%$ for a heterogeneity test, a random-effects model was chosen to reduce the effects of heterogeneity. Second, in the subgroup analyses, the sample size of some cancer types was really small, which may affect the stability of our pooled results. Therefore, more high-quality reports are needed to validate the clinical value of miR224-5p in various types of digestive system malignancies. Third, the credibility of miR-224$5 p$ target gene prediction results was increased by combining 12 miRNA-target prediction programs. However, no in vitro and in vivo experimental verification was a weakness in the present study. Thus, further studies are required to confirm the target genes and pathways of miR-224-5p and the molecular mechanism within the network.

In summary, the current study gathered 41 microarray and RNA-seq datasets and 11 published studies to validate the up-regulation of miR-224-5p and discover its diagnostic and prognostic value in cancers of the digestive tract. Twelve miRNA-target prediction programs were used to predict the potential target mRNAs of miR-224-5p. In total, 388 target mRNAs, which were simultaneously predicted by at least eight prediction programs, were extracted for GO annotation and KEGG pathway enrichment analysis. The results highlighted the multiple genes and signaling pathways targeted by miR-224-5p. However, the exact molecular mechanisms of miR-224-5p in digestive system cancers remain confusing and demand further study. We hope our study may provide a basis for further clinical application of miR-224-5p in digestive system cancers. 


\section{Cellular Physiology Cell Physiol Biochem 2017;44:682-700

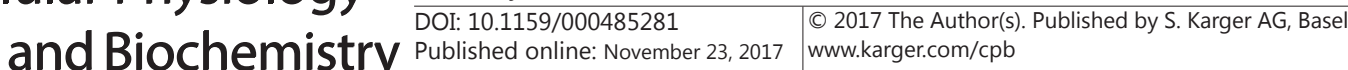

Zhang et al.: MiR-224-5p in Cancers of the Digestive Tract

\section{Disclosure Statement}

The authors declare no Disclosure Statement.

\section{Acknowledgements}

This study is supported by the Fund of National Natural Science Foundation of China (NSFC81560386). It was also supported by the public databases of Gene Expression Omnibus, The Cancer Genome Atlas and ArrayExpress.

\section{References}

1 Siegel RL, Miller KD, Jemal A: Cancer Statistics, 2017. CA Cancer J Clin 2017;67:7-30.

2 Cheng CJ, Bahal R, Babar IA, Pincus Z, Barrera F, Liu C, Svoronos A, Braddock DT, Glazer PM, Engelman DM, Saltzman WM, Slack FJ: MicroRNA silencing for cancer therapy targeted to the tumour microenvironment. Nature 2015;518:107-110.

- 3 Png KJ, Halberg N, Yoshida M, Tavazoie SF: A microRNA regulon that mediates endothelial recruitment and metastasis by cancer cells. Nature 2011;481:190-194.

4 Sumazin P, Yang X, Chiu HS, Chung WJ, Iyer A, Llobet-Navas D, Rajbhandari P, Bansal M, Guarnieri P, Silva J, Califano A: An extensive microRNA-mediated network of RNA-RNA interactions regulates established oncogenic pathways in glioblastoma. Cell 2011;147:370-381.

-5 Armand-Labit V, Pradines A: Circulating cell-free microRNAs as clinical cancer biomarkers. Biomol Concepts 2017;10.1515/bmc-2017-0002

-6 Xue J, Niu J, Wu J, Wu ZH: MicroRNAs in cancer therapeutic response: Friend and foe. World J Clin Oncol 2014;5:730-743.

7 Xie T, Huang M, Wang Y, Wang L, Chen C, Chu X: MicroRNAs as Regulators, Biomarkers and Therapeutic Targets in the Drug Resistance of Colorectal Cancer. Cell Physiol Biochem 2016;40:62-76.

8 Hu K, Liang M: Upregulated microRNA-224 promotes ovarian cancer cell proliferation by targeting KLLN. In vitro Cell Dev Biol Anim 2017;53:149-156.

-9 Huang Y, Li Y, Wang FF, Lv W, Xie X, Cheng X: Over-Expressed miR-224 Promotes the Progression of Cervical Cancer via Targeting RASSF8. PLoS One 2016;11:e0162378.

10 Liu F, Liu Y, Shen J, Zhang G, Han J: MicroRNA-224 inhibits proliferation and migration of breast cancer cells by down-regulating Fizzled 5 expression. Oncotarget 2016;7:49130-49142.

11 Cui R, Kim T, Fassan M, Meng W, Sun HL, Jeon YJ, Vicentini C, Tili E, Peng Y, Scarpa A, Liang G, Zhang YK, Chakravarti A, Croce CM: MicroRNA-224 is implicated in lung cancer pathogenesis through targeting caspase-3 and caspase-7. Oncotarget 2015;6:21802-21815.

12 Wan Y, Zeng ZC, Xi M, Wan S, Hua W, Liu YL, Zhou YL, Luo HW, Jiang FN, Zhong WD: Dysregulated microRNA-224/apelin axis associated with aggressive progression and poor prognosis in patients with prostate cancer. Hum Pathol 2015;46:295-303.

13 Zhang Y, Li CF, Ma LJ, Ding M, Zhang B: MicroRNA-224 aggrevates tumor growth and progression by targeting mTOR in gastric cancer. Int J Oncol 2016;49:1068-1080.

14 Li T, Lai Q, Wang S, Cai J, Xiao Z, Deng D, He L, Jiao H, Ye Y, Liang L, Ding Y, Liao W: MicroRNA-224 sustains Wnt/beta-catenin signaling and promotes aggressive phenotype of colorectal cancer. J Exp Clin Cancer Res 2016;35:21.

15 Li Q Ding C, Chen C, Zhang Z, Xiao H, Xie F, Lei L, Chen Y, Mao B, Jiang M, Li J, Wang D, Wang G: miR-224 promotion of cell migration and invasion by targeting Homeobox D 10 gene in human hepatocellular carcinoma. J Gastroenterol Hepatol 2014;29:835-842.

16 He X, Zhang Z, Li M, Li S, Ren L, Zhu H, Xiao B, Shi R: Expression and role of oncogenic miRNA-224 in esophageal squamous cell carcinoma. BMC Cancer 2015;15:575.

17 Tierney JF, Stewart LA, Ghersi D, Burdett S, Sydes MR: Practical methods for incorporating summary timeto-event data into meta-analysis. Trials 2007;8:16. 


\section{Cellular Physiology Cell Physiol Biochem 2017;44:682-700 \begin{tabular}{l|l|l}
\hline and Biochemistry $10.1159 / 000485281$ & $\begin{array}{l}\text { C } 2017 \text { The Author(s). Published by S. Karger AG, Basel } \\
\text { www.karger.com/cpb }\end{array}$ \\
\hline
\end{tabular}}

Zhang et al.: MiR-224-5p in Cancers of the Digestive Tract

18 Lau J, Ioannidis JP, Schmid CH: Quantitative synthesis in systematic reviews. Ann Intern Med 1997;127:820-826.

19 Higgins JP, Thompson SG, Deeks JJ, Altman DG: Measuring inconsistency in meta-analyses. BMJ 2003;327:557-560.

20 Ji W, Sun B, Su C: Targeting MicroRNAs in Cancer Gene Therapy. Genes (Basel) 2017;8:

21 Sun L, Chua CY, Tian W, Zhang Z, Chiao PJ, Zhang W: MicroRNA Signaling Pathway Network in Pancreatic Ductal Adenocarcinoma. J Genet Genomics 2015;42:563-577.

-22 Li HT, Zhang H, Chen Y, Liu XF, Qian J: MiR-423-3p enhances cell growth through inhibition of p21Cip1/ Waf1 in colorectal cancer. Cell Physiol Biochem 2015;37:1044-1054.

23 Du Y, Li J, Xu T, Zhou DD, Zhang L, Wang X: MicroRNA-145 induces apoptosis of glioma cells by targeting BNIP3 and Notch signaling. Oncotarget 2017;10.18632/oncotarget.18604

24 Zhu P, Zhang J, Zhu J, Shi J, Zhu Q, Gao Y: MiR-429 Induces Gastric Carcinoma Cell Apoptosis Through Bcl-2. Cell Physiol Biochem 2015;37:1572-1580.

25 Gozuacik D, Akkoc Y, Ozturk DG, Kocak M: Autophagy-Regulating microRNAs and Cancer. Front Oncol 2017;7:65.

26 Ghahhari NM, Babashah S: Interplay between microRNAs and WNT/beta-catenin signalling pathway regulates epithelial-mesenchymal transition in cancer. Eur J Cancer 2015;51:1638-1649.

27 Ayers D, Vandesompele J: Influence of microRNAs and Long Non-Coding RNAs in Cancer Chemoresistance. Genes (Basel) 2017;8:

28 Pinweha P, Rattanapornsompong K, Charoensawan V, Jitrapakdee S: MicroRNAs and oncogenic transcriptional regulatory networks controlling metabolic reprogramming in cancers. Comput Struct Biotechnol J 2016;14:223-233.

29 Huang L, Dai T, Lin X, Zhao X, Chen X, Wang C, Li X, Shen H, Wang X: MicroRNA-224 targets RKIP to control cell invasion and expression of metastasis genes in human breast cancer cells. Biochem Biophys Res Commun 2012;425:127-133.

-30 Cui R, Meng W, Sun HL, Kim T, Ye Z, Fassan M, Jeon YJ, Li B, Vicentini C, Peng Y, Lee TJ, Luo Z, Liu L, Xu D, Tili E, Jin V, Middleton J, Chakravarti A, Lautenschlaeger T, Croce CM: MicroRNA-224 promotes tumor progression in nonsmall cell lung cancer. Proc Natl Acad Sci U S A 2015;112:E4288-4297.

-31 Lu S, Wang S, Geng S, Ma S, Liang Z, Jiao B: Upregulation of microRNA-224 confers a poor prognosis in glioma patients. Clin Transl Oncol 2013;15:569-574.

32 Mavridis K, Stravodimos K, Scorilas A: Downregulation and prognostic performance of microRNA 224 expression in prostate cancer. Clin Chem 2013;59:261-269.

33 Ni H, Wang X, Liu H, Tian F, Song G: Low expression of miRNA-224 predicts poor clinical outcome in diffuse large B-cell lymphoma treated with R-CHOP. Biomarkers 2015;20:253-257.

34 Zhi F, Shao N, Li B, Xue L, Deng D, Xu Y, Lan Q Peng Y, Yang Y: A serum 6-miRNA panel as a novel noninvasive biomarker for meningioma. Sci Rep 2016;6:32067.

35 Yu L, Zhang J, Guo X, Li Z, Zhang P: MicroRNA-224 upregulation and AKT activation synergistically predict poor prognosis in patients with hepatocellular carcinoma. Cancer Epidemiol 2014;38:408-413.

-36 Wang Y, Toh HC, Chow P, Chung AY, Meyers DJ, Cole PA, Ooi LL, Lee CG: MicroRNA-224 is up-regulated in hepatocellular carcinoma through epigenetic mechanisms. FASEB J 2012;26:3032-3041.

-37 Adamopoulos PG, Kontos CK, Rapti SM, Papadopoulos IN, Scorilas A: miR-224 overexpression is a strong and independent prognosticator of short-term relapse and poor overall survival in colorectal adenocarcinoma. Int J Oncol 2015;46:849-859.

-38 Liao WT, Li TT, Wang ZG, Wang SY, He MR, Ye YP, Qi L, Cui YM, Wu P, Jiao HL, Zhang C, Xie YJ, Wang JX, Ding YQ: microRNA-224 promotes cell proliferation and tumor growth in human colorectal cancer by repressing PHLPP1 and PHLPP2. Clin Cancer Res 2013;19:4662-4672.

39 He C, Wang L, Zhang J, Xu H: Hypoxia-inducible microRNA-224 promotes the cell growth, migration and invasion by directly targeting RASSF8 in gastric cancer. Mol Cancer 2017;16:35.

40 Mees ST, Mardin WA, Sielker S, Willscher E, Senninger N, Schleicher C, Colombo-Benkmann M, Haier $\mathrm{J}$ : Involvement of CD40 targeting miR-224 and miR-486 on the progression of pancreatic ductal adenocarcinomas. Ann Surg Oncol 2009;16:2339-2350. 


\section{Cellular Physiology Cell Physiol Biochem 2017;44:682-700 \begin{tabular}{l|l|l} 
DOI: 10.1159/000485281 & $\begin{array}{l}\text { O 2017 The Author(s). Published by S. Karger AG, Basel } \\
\text { www.karger.com/cpb }\end{array}$ \\
\hline
\end{tabular}}

Zhang et al.: MiR-224-5p in Cancers of the Digestive Tract

41 Fiorino S, Bacchi-Reggiani ML, Visani M, Acquaviva G, Fornelli A, Masetti M, Tura A, Grizzi F, Zanello M, Mastrangelo L, Lombardi R, Di Tommaso L, Bondi A, Sabbatani S, Domanico A, Fabbri C, Leandri P, Pession A, Jovine E, de Biase D: MicroRNAs as possible biomarkers for diagnosis and prognosis of hepatitis B- and C-related-hepatocellular-carcinoma. World J Gastroenterol 2016;22:3907-3936.

-42 Lin L, Lu B, Yu J, Liu W, Zhou A: Serum miR-224 as a biomarker for detection of hepatocellular carcinoma at early stage. Clin Res Hepatol Gastroenterol 2016;40:397-404.

-43 Sohn W, Kim J, Kang SH, Yang SR, Cho JY, Cho HC, Shim SG, Paik YH: Serum exosomal microRNAs as novel biomarkers for hepatocellular carcinoma. Exp Mol Med 2015;47:e184.

-44 Okajima W, Komatsu S, Ichikawa D, Miyamae M, Kawaguchi T, Hirajima S, Ohashi T, Imamura T, Kiuchi J, Arita T, Konishi H, Shiozaki A, Moriumura R, Ikoma H, Okamoto K, Taniguchi H, Itoh Y, Otsuji E: Circulating microRNA profiles in plasma: identification of miR-224 as a novel diagnostic biomarker in hepatocellular carcinoma independent of hepatic function. Oncotarget 2016;7:53820-53836.

45 Chen W, Fan XM, Mao L, Zhang JY, Li J, Wu JZ, Tang JH: MicroRNA-224: as a potential target for miR-based therapy of cancer. Tumour Biol 2015;36:6645-6652.

46 Amankwatia EB, Chakravarty P, Carey FA, Weidlich S, Steele RJ, Munro AJ, Wolf CR, Smith G: MicroRNA-224 is associated with colorectal cancer progression and response to 5-fluorouracil-based chemotherapy by KRAS-dependent and -independent mechanisms. Br J Cancer 2015;112:1480-1490.

47 Ling H, Pickard K, Ivan C, Isella C, Ikuo M, Mitter R, Spizzo R, Bullock M, Braicu C, Pileczki V, Vincent K, Pichler M, Stiegelbauer V, Hoefler G, Almeida MI, Hsiao A, Zhang X, Primrose J, Packham G, Liu K, Bojja K, Gafa R, Xiao L, Rossi S, Song JH, Vannini I, Fanini F, Kopetz S, Zweidler-McKay P, Wang X, Ionescu C, Irimie A, Fabbri M, Lanza G, Hamilton SR, Berindan-Neagoe I, Medico E, Mirnezami A, Calin GA, Nicoloso MS: The clinical and biological significance of MIR-224 expression in colorectal cancer metastasis. Gut 2016;65:977989. 